\title{
Assessing Unemployment Traps in Belgium using Panel Data Sample Selection Models
}

\author{
Anna Cristina D'Addio* \\ CIM, Aarhus School of Business; Department of Economics, University of Aarhus; \\ Isabelle De Greef ${ }^{\dagger}$ \\ IRES, Université Catholique de Louvain \\ Michael Rosholm $\ddagger$ \\ Department of Economics, University of Aarhus, IZA Bonn, CIM
}

March, 2002

\begin{abstract}
In this paper we investigate whether unemployment traps exist and are significant in the transition from unemployment into employment in Belgium. In order to assess them, we use panel data sample selection models. Specifically, we estimate a parametric random effects models composed by a wage equation and a selection equation by maximum likelihood techniques. The income ratios have been computed for every individual in the sample by using the predicted wages obtained from the estimation of the wage equation corrected for sample selectivity. The empirical analyses has exploited the data extracted from the waves 1993-1997 of the Panel Study of Belgian Household and has been led separately on (unbalanced) samples of men and women. The estimation results suggest significant differences in the behaviour of these two groups.The experience of long periods of unemployment in the past is particularly important: long-term unemployed people have difficulties in re-integrating the labour market and they obtain low salaries when they succeed in finding employment. Long unemployment spells are likely to have a "scarring" effect on subsequent earnings. Moreover, the computation of income ratios for all individuals highlights the importance of unemployment traps for the women present in the sample. Indeed, their expected wage is often lower than their income while being unemployed. A significant proportion of the available samples (men and women) is shown to enter employment although this transition is accompanied by a substantial loss in their disposable income.
\end{abstract}

Keywords: Panel data sample selection models, wage equation, predicted wages, unemployment traps, scarring effect

JEL Classifications: C33, C34, J33

\footnotetext{
*Mailing address: Department of Economics, University of Aarhus; Universitetparken, Building 326, DK-8000, Aarhus. e-mail: adaddio@econ.au.dk

${ }^{\dagger}$ Corresponding author, IRES AXE 4, Place Montesquieu, 3, 1348 Louvain-la-Neuve, Belgium. e-mail: degreef@ires.ucl.ac.be

${ }^{\ddagger}$ Mailing address: Department of Economics, University of Aarhus; Universitetparken, Building 326, DK-8000, Aarhus. e-mail: rom@cls.dk
} 


\section{Introduction}

The combination of unemployment benefits, high labour taxes, social contributions and conditional transfers such as additional child benefits, can occasionally reduce the willingness of the (low-skilled) unemployed to find and/or to accept a job (OECD, 1996; 1999). Insignificant financial returns associated with job holding compared to unemployment benefits may affect the decision of moving into unemployment especially for the low-educated unemployed and thereby contribute to the persistence of unemployment.

The situation in which households or individuals have no incentives (financial and/or non financial) to leave unemployment (for employment) is termed an "unemployment trap". Broadly speaking, we can distinguish two main approaches in the study of financial unemployment traps, i.e. unemployment traps stemming from the lack of financial incentives to move into employment. The first approach is based on "representative" households or individuals (see OECD,1996, 1999; and for Belgium see e.g. De Lathouwer, 2001; Defeyt, 1998). The second approach exploits real data in setting up empirical analyses. Our study is developed within the second approach.

Most of the existing evidence concerning financial incentives has been provided within the first approach based on the construction of various categories of households by making several assumptions. The idea behind the use of representative households is to compute the change in the household's disposable income that would result from the transition to employment of the unemployed member. Households are trapped in unemployment if the ratio between the disposable income in unemployment and the disposable income in employment is close to or above 100 per cent: for Belgium, the analysis with representative households show that unemployment traps arise mainly for single-parent families. While the analysis with "representative" households are very useful, they only try answering to the question: "What types of family have the highest probability to be trapped in unemployment?" Nevertheless, those studies do not suffer from incomplete income information, inaccuracy and measurement errors that are inherent to empirical work, especially to studies dealing with earnings.

Within the second approach, some recent studies have focused on the computation of the variation in the disposable income (individual or household's disposable income) resulting from moving from unemployment to employment. Among them, for instance, Pedersen and Smith (2001) report for Denmark that during the nineties a high percentage of the Danish unemployed were facing unemployment traps. For Finland, Kyyrä (1999) also reports that a significant percentage of unemployed individuals were unable to increase their household's disposable income by exiting to employment.

Up to now few empirical studies have estimated a wage function on the grounds of Belgian data sets. Moreover, only one is based on a panel data set (see Laurent, 2001). The purpose of our study is therefore to investigate the financial rewards linked to the transition from unemployment to employment for Belgian individuals for the years 1993-1997. In doing this, we use micro-data extracted from the Panel Study of Belgian Household (PSBH). Specifically, 
the sample used in this paper is drawn from the waves 3 to 7 of the Panel Study of Belgian households (PSBH) concerning the years 1993 to 1997, and is constructed by using the retrospective calendar of activity and the annual net income of the sampled individuals. Besides financial incentives, we are interested also in non-financial incentives (e.g. the valuation of work, the day structure, the taste for social contacts, etc.) since these may also play a role in the job decision process and for some individuals they can overrule the effects of the financial incentives. Nevertheless our interest in non-financial incentives is limited by the available data.

Our study, differently from the first approach described above, is not based on representative households but on real data. This way of proceeding will allow us to obtain estimates of the "real-life" incentives. Moreover, our paper differs from the majority of studies that have been carried out within the second approach. Whereas some of those papers use longitudinal data (e.g. Pedersen and Smith, 2001; Kyyrä, 1999), they don't duly account for the sample selection problem in the wage equation. In the present paper we address the question of unemployment traps by using panel data estimation techniques and by correcting for the sample selection problem (Heckman, 1979) within that modelling framework.

Sample selection models are frequently estimated in applied microeconometric work using cross-sectional data, but they are less frequently applied when panel data are available. By ignoring this aspect of the data, the sample selection process is therefore supposed to be constant over time, and the argument crucial to this assumption is that standard panel data estimators eliminate sample selection bias since they difference out both the unobserved individualspecific effect and the sample selection effect (see Jensen et al., 2001). Nevertheless, despite the greater complexity of the task, we believe that when panel data are available, a natural way of dealing with the sample selection problem is the one exploiting panel sample selection models since, in general there is no reason to believe that the sample selection process is time-invariant: unobservable time-varying variables may occur in both the selection equation and the equation of interest, and they may exhibit a complex correlation structure. Modelling sample selection by using panel data techniques, allows us accounting for it being possibly time-varying. To this end, we estimate simultaneously by maximum likelihood a parametric panel data random effects model composed by two equations: a wage equation and a selection equation.

In both of the approaches mentioned, the construction of the wages that unemployed people would earn when employed is crucial. Indeed, financial incentives are measured through the estimation of the individuals' replacement ratios, defined as the ratio between the individual disposable income when employed and the individual disposable income when unemployed. A crucial component of the disposable income is the wage. However, wages (i.e. post-unemployment wages) can be observed only for people moving into employment after a spell of unemployment.

As will be seen in section 4, we have used the expected wage predicted on the grounds of the estimates of the wage equation to compute the replacement ratio for all the individuals in the sample (including those that have not moved 
out of unemployment over the whole survey period). This allows us to compute an observed replacement ratio and an estimated replacement ratio as in Kyyrä (1999). While the observed replacement ratio is based on the observed wage earned by the individuals who move into work, the estimated one is based on the expected wage for individuals that have not moved into employment. In addition, for the individuals that move into employment this way of proceeding makes it possible to compare the observed individual replacement ratio with the estimated one.

The paper is organized as follows. Section 2 outlines the Belgian tax system and the Belgian unemployment insurance scheme. In Section 3, we present a survey of the studies dealing with the issue of financial incentives in the transition out of unemployment. Section 4 presents the econometric model we have applied here. Section 5 is devoted to the description of the dataset, section 6 reports and discusses the results obtained. Some conclusions are drawn in section 7 .

\section{Tax and Unemployment insurance schemes in Bel- gium}

Different studies have shown how important and persistent the problem of unemployment is in Belgium. Besides arguments about the structural nature of the problem, it is likely that the features of the existing tax scheme contribute to make people less willing to accept jobs. In addition to the fact that unemployed individuals have not to contribute to the social security, when they move into work the fiscal burden increases more than the progressiveness of the tax scale: unemployment benefits - more generally replacement incomes - are subjected to a higher level of tax exemption than labour earnings.

Financial traps occur when the gap between net wages and unemployment benefits is small. Nevertheless the difference between unemployment benefits and wages is not the only factor that matters. Some transfers - merely the additional child benefits and the supplementary interventions of the state in health care costs - are conditional on unemployment and disappear when the unemployed move into work. Moreover, some specific support is granted to low-incomes households. For instance, although there are no housing benefits in Belgium, families with low incomes could benefit of social housing for which they pay a moderate rent.

Further, unemployed people (heads of households) having spent at least six months in unemployment, are entitled to additional child benefits. These additional child benefits are withdrawn if the unemployed accepts a job for more than 14 days. It is also true that unemployed people moving into work are granted a tax exemption for each child. However, some households with low incomes do not pay taxes and therefore they can not benefit of it. Finally, an unemployed individual who looses his job, has to wait six months to be qualified again for these additional payments.

The sudden removal of conditional transfers reduces work incentives especially for temporary jobs. The legislation concerning additional child benefits 
has been recently improved and some additional measures have been taken up in order to make work more attractive for unemployed individuals. Four major reforms have been implemented since January 2000 on work incentives.

First, the social security contributions paid by the employees have been reduced for low-income workers. This reform, extended in April 2000, is restricted to wage earners with a gross monthly wage below 1,338 euros. The payment of contributions to social insurance is reduced by a specific amount that decreases as wage increases. At the minimum guaranteed gross wage (1,103 euros) the reduction of social contributions is maximal (81.8 euros). Over this level, it tends progressively to zero. The new reform of the tax system that will be implemented this year (2002) introduces a negative income tax for the low-income workers; as a consequence the net income of work will increase. Second, child care costs are fully deductible since January 2000 (compared to 80 per cent in the past) but the tax exemption is limited to 11.1 euros by day and child (compared to 8.5 euros before). Third, since July 2000, long-term unemployed who accept a job located at more than 25 kilometers from their home receive an one-shot subsidy of 743.7 euros. The same amount is allocated to unemployed single-parents who accept a job. Fourth, the legislation on additional child benefits has been modified in order to encourage the unemployed heads of household to accept temporary jobs: unemployed people moving into work and, loosing their job during the first 6 months following unemployment, are entitled immediately to additional child benefits. Finally, the unemployed who accept a temporary job (the duration of which should be less than 27 days) and for whom the unemployment duration is shorter than 6 months have to wait only 2 months after the end of their contract to be entitled again to additional child benefits.

Since the data used in this study covers the years 1993-1997, the following description of both the unemployment insurance scheme and the tax system concerns this period. All the amounts reported in this section are related to the year 1997.

\subsection{Unemployment Insurance Scheme}

The Belgian unemployment insurance scheme is characterized on one hand by a generous level of benefits, especially for people with low income (high replacement ratios), and on the other hand by an indefinite entitlement period. The payment of unemployment benefits can however be suspended for unemployed people who are living with a working partner or with their parents ("cohabitants") depending on a certain number of conditions (for more details see De Greef, 2000).

In order to be eligible for unemployment benefits, the individuals must have been employed for a relatively long period. The length of the employment period varies with the age of the individuals: for instance, on the first day of unemployment, individuals aged less than 36 must have been employed for 312 days during the latest 18 months. To receive unemployment benefits the individual should be involuntary unemployed, available on the labour market, and actively seeking work. 
Moreover, the entitlement to unemployment benefits depends on previous employment experience (only for the wage earners), on the schooling curricula, and on having received unemployment benefits in the past. The level of unemployment benefits depends on four elements: the composition of the household, the length of unemployment, the age, and the previous wage.

Concerning the household composition, three categories are identified: (1) heads of household, (2) "singles", i.e. individuals who are living on their own; (3) "cohabitants", i.e. individuals belonging to families where other members earn more than 170.7 euros monthly net or receive a substitution income (secondary earners). Those three categories receive different levels of unemployment benefits: the heads of household are entitled to a high level of benefits, the "singles" are qualified to a medium level of benefits and the "cohabitants" receive the lowest level of unemployment benefits. In addition, the amount of the unemployment benefits is constant over time for the heads of household (60 per cent of the previous wage) whereas it decreases for the singles (from 60 per cent the first year to 42 per cent the second year) and for the cohabitants (from 55 per cent the first year to 35 per cent the first quarter of the second year and to a lump sum the second quarter of the second year). The cohabitants are therefore entitled to three periods of subsidization, however if they have been employed for more than 20 years they benefit "forever" of the second period compensation ( $35 \%$ of the previous wage).

The amount of unemployment benefits depends on previous labour earnings but it is upwards and downwards bounded. For instance, unemployment benefits for the heads of household are set between a maximum of 864.9 euros and a minimum of 759.3 euros.

Finally, the level of benefits is based on the age. Unemployed individuals aged more than 50 receive an additional amount. This supplement, conditional on having worked more than 20 years, varies according to the household type and the age of the individual.

Since 1987, unemployed have had the opportunity to increase the amount of benefits by working for an Agence locale pour l'emploi, (i.e. "local agency for employment") with a maximum of 45 hours per month ${ }^{1}$ and they receive 3.72 euros for each hour worked. The "jobs" (although they are not real jobs since that the individuals' labour status is still that of unemployed) proposed by these local agencies are mainly housework and child care.

\subsection{The tax system}

The tax system consists of social security contributions and a progressive income tax; an additional local income tax is levied on taxable income at an average rate of $7 \%$. Social security contributions paid by the employees correspond to 13.07 per cent of gross earnings. Spouses are taxed separately; however if they have no labour income or if the labour income of one of the spouses is less than 30 per cent of the household's labour earnings, 30 per cent of the net household labour income (minus the labour income of the spouse) is attributed

\footnotetext{
${ }^{1}$ The system of local agency for employment has been modified in 1994. Before 1994 the amount of hours worked was limited to 60 hours per month.
} 
to the partner. The amount fictionally transferred to the spouse with low or no labour income is limited to 7,362.4 euros.

Several tax allowances exist in the Belgian tax scheme. Each individual is granted a personal income exemption; the amount of this tax allowance depends on the family composition. If a married partner can not use his own income's tax exemption because his personal labour income is too low, this amount may be attributed to the spouse. The other main tax allowances are related to the number of children, child care costs, work related expenses. In addition, the amount of the tax exemption is higher for replacement incomes (e.g. pensions, unemployment benefits) than for labour earnings.

The tax schedule prevailing in Belgium in 1997 is detailed in Table 1 in the Appendix.

[Table 1 to be inserted here]

\section{Financial incentives: previous evidence}

Two approaches have been mainly used in the investigation of the financial rewards linked to the transition from unemployment to employment. Besides this, various authors have focused on whether past unemployment experience has a scarring effect on subsequent earnings. We discuss some of the main findings of these studies in this section.

A majority of researches on financial incentives have been carried out in the US and in United-Kingdom where in-work benefits (i.e. benefits that increase the work incentives of those with low potential returns in the labour market by raising the income gap between working and not working) have been implemented. However, a large part of the literature on work incentives deals with the impact of welfare transfers (and the modification in the eligibility requirements) on the labour supply of single-parent families.

The key variable in the analysis of financial incentives consists in the net replacement ratio from holding a job relative to receiving unemployment benefits and its computation varies according to the modelling approach chosen (see Atkinson and Micklewright, 1991).

A first approach computes it through simulations with representative households and/or individuals with the aim of identifying the types of family with the highest probability to be financially trapped. The analysis with representative households is relevant and rich of details, but the detection of financial traps by using representative households does not necessarily imply that individuals are really influenced by traps. Nothing is said about the real-life financial incentives. Considering for instance, the same net income gap between work and unemployment, it may happen that one individual decides to move into employment whereas another refuses the job because the financial incentives are too low. The studies with representative households do not take the heterogeneity of individuals into account. Further, the unemployed are assumed to have a fully rational behavior although this does not always correspond to the reality because of a misunderstanding or a lack of knowledge concerning the rules of the tax and benefits systems. 
In this literature, representative households are constructed on the grounds of various assumptions. These assumptions concern, among others, the previous length of unemployment, the composition of the household (singles, households with only one working partner, households with two wage earners, singleparent families, etc.), the number and the age of the children (child care costs) and the level of wages. Several authors (e.g. Saunders et al., 1989) have argued that replacement ratios obtained on the grounds of representative households/individuals are of modest relevance to study the question of work incentives in the absence of statistics on the number of individuals in such hypothetical situations. Despite this, most of the existing evidence on financial incentives has been obtained within this literature.

A second approach has been developed and it uses empirical data and econometric techniques to obtain the replacement ratios. However, the number of studies in this field are still rare and this is certainly linked to the lack of "good" data on earnings and to the difficulty of some methodological problems.

Within the literature using representative households/ individuals, unemployment traps arise when the replacement ratio is close to or above 100 per cent. This ratio can be computed either at the individual level (OECD, 1999) or at the household level: for instance, the individual replacement ratio calculated by the OECD since 1961 is based on the earnings of an average production worker $(\mathrm{APW})^{2}$. This ratio doesn't account for taxation, family and housing benefits. It is derived from an average of 18 "stylized" individuals obtained by combining three unemployment durations ( 1 year, 2-3 years, $4-5$ years), three kinds of households (single, married and head of household, married with an earning partner) and two wage levels (APW and $2 / 3 \mathrm{APW}$ ). The eighteen "representative" individuals are 40 years old and have a long work experience that avoids them to receive a lump sum unemployment benefit. Another index available since 1995 takes into account the effects of taxation and of others transfers (OECD, 1999).

The studies with "stylized" households very barely account for commuting costs, additional intervention in health care, and social housing rents that are likely to increase the occurrence of financial traps. In the Belgian case, the studies with representative households (see e.g. De Lathouwer, 2001, and Defeyt, 1998) consider the following components to build the disposable income of the households: wages, unemployment benefits, social contributions and taxes (including the allowance for children and the tax exemption for child care costs), child benefits, additional child benefits and child care costs. Replacement ratios are computed at the same time for a maximal and a minimal level of unemployment benefits. Their main results can be summarized as follows.

First, concerning the transition from unemployment to full time work, the studies show that single-parent families and some households with only one source of income (e.g. the one earner's families entitled to a maximum level of benefits and that accept a job paid at the minimum wage) are more exposed to

\footnotetext{
${ }^{2}$ The average production worker is defined as "an adult full-time production worker in the manufacturing sector whose wage earnings are equal to the average wage earnings of such workers".
} 
unemployment traps than others types of households. The gap between wage and unemployment benefits is obviously important. However, the unemployment traps also depend on the end of entitlement to conditional transfers which occurs when the unemployed individuals decide to move into work as in the case of additional child benefits which are withdrawn when the unemployed accept a job for more than 14 days. This sudden change does not favour the transition to employment and especially to temporary jobs.

Second, the transition from unemployment to part-time jobs does not lead to a large increase in the disposable income, except for the singles. In addition, unemployed people who move into a part-time job never know a loss of income. This is due to the existence of a compensation mechanism called allocation de garantie de revenu, implemented in 1993, which guarantees that individuals who accept a part-time job obtain an income greater than the amount of unemployment benefits whatever the level of wage considered and the hours worked. If the level of the wage is lower than the level of the unemployment benefits, the workers will be paid the difference from the state. This difference is increased by a lump sum the amount of which depends on the household composition: 134.1 euros for the heads of household, 107.3 euros for the singles and 80.5 euros for the cohabitants. However, the lump sum appears to be too small to influence significantly the transition from unemployment to part-time jobs. Moreover, since this subsidy is withdrawn when the hours worked are equivalent to 80 per cent of a full-time job, the transition from part-time to full-time is discouraged.

Various studies have been developed within the approach based on real data. However, the number of those investigating how the probability of moving from unemployment into employment is influenced by the unemployment compensation schemes - in terms of unemployment traps (see e.g. OECD, 2002; Pedersen and Smith, 2001; Kyyrä, 1999; Gregg et al., 1999; and Holm et al., 1999) is not yet large compared to those focusing on the earning losses associated with the experience of unemployment (e.g. Nickell, 1999; Arulampalam, 2000).

A majority of the literature on unemployment has conventionally assumed that the wages of the individuals that have experienced an unemployment spell are equal to those obtained by employed individuals with the same characteristics (e.g. Layard et al., 1991). This assumption is implicitly based on the fact that differences in wages are only due to differences in observed characteristics (e.g. age, sex, education). In order to avoid a potential bias caused by unobserved heterogeneity that affects both the probability of being in work and the wage level, some studies adopt a correction for sample selection: if the decision to work is affected by the expected earnings, it is possible that individuals who are currently working have higher wages than those that would be earned by the unemployed individuals. In that sense, the correction for potential selection bias accounts for the non-randomness of the selection process into employment: wages are observed only for those who are employed, i.e. for those for whom the wage exceeds the reservation wage.

The assumptions used to compute the expected wages of individuals who are currently out of work is crucial to determine the financial returns associated with job holding and they vary across the different studies. Some of those studies have used the wages obtained in the last job prior to unemployment (only when 
the unemployed have been employed before their unemployment spell, OECD, 1996, 1999). Others have exploited the unemployed's own expectations about the wages they would get in a future job (Pedersen and Smith, 2001), or the average wage obtained by people who are employed. Finally some of them are based on the expected wage adjusted for selectivity, on the wage obtained by workers after an unemployment experience (post-unemployment wages), or on post-unemployment wages corrected for sample selection bias (Kyyrä, 1999).

Concerning this way of proceeding, some authors (see e.g. Gregg et al., 1999, and Kyyrä, 1999) argue that the use of average or expected wages - even if they have been adjusted for selectivity - to study the financial incentives faced by the unemployed may produce upward-biased estimates of the returns to employment, since the experience of unemployment, particularly the length of the unemployment spell, may affect productivity as well as the reservation wage.

To determine how the probability of moving from non-employment into work is affected both by an increase of predicted out-of-work income and a rise of expected gains from working, Gregg et al. (1999) compare the distribution of hourly wages for employed workers with the distribution of hourly re-entry wages (wages reported by individuals moving from non-employment into employment). The research of Gregg et al. is based on two UK data sets: the Quarterly Labour Force Survey (QLFS) and the Family Resources Survey (FRS). A tax and benefit microsimulation model (TAXBEN from the Institute for Fiscal Studies (IFS)) is implemented on the data in order to evaluate the post-tax and benefit income in and out-of-work. The authors restrict their attention to a sample of individuals aged between 18 and 59 (excluding the students, the severely disabled, and the individuals who moved into self-employment) not working during the Summer of 1994. Moreover, they consider only the labour market status at the beginning and the end of the panel: by construction the individuals are observed to have at most one change of labour market status.. Gregg et al. (1999) show that the shape of the wage distribution of employed workers differs from the shape of the re-entry wage distribution. The former is close to a normal distribution whereas the latter is more concentrated on lower wage levels: the re-entry wage distribution has a lower mean than the overall wage distribution while the median re-entry wage is around 69 per cent of the median for the overall wage distribution. A large part of the divergence between the two distributions is shown to depend on differences in individual characteristics (e.g. concerning job tenure) and on differences in job attributes in the two populations. In order to derive the wages that individuals who are out-of-work would be able to earn if they move into work, Gregg and al. (1999) also compare the results from different wage estimations (based on the overall wage distribution, the overall wage assumption adjusted for self-selection, and the re-entry wage distribution without selectivity correction). They find that the expected wages for the individuals currently out-of-work are lower if the re-entry wage distribution is used. They emphasize also that the differences due to gender and to education are weaker for the re-entry wages than for the overall wage distribution. Finally, in analyzing the entry/re-entry into work after a period of unemployment or inactivity in United Kingdom, they compute 
a replacement ratio (respectively for 12, 20 and 37 hours of work) defined as "the ratio of income net of taxes and benefits when out of work to net income in work" by using various assumptions concerning the wages. The use of entry wages leads to a predicted replacement rate for a full-time job (37 hours a week) of 70 per cent against 60 per cent on the grounds of the average wage for employed workers. This replacement ratio is shown to decrease with the number of hours worked. Moreover, gender and household composition are responsible for substantial differences in the financial returns associated with moving into work. Still, the net replacement ratio is found to be higher for married individuals with a non-working partner comparing with married individuals with a working partner.

The study of Kyyrä (1999) for Finland, reports that the distribution of postunemployment wages is leftward-skewed and more compressed than the overall wages distribution. The empirical analysis of Kyyrä is based on two samples. The first one is obtained by pooling individuals flowing out of the unemployment register in 1988, 1990, 1992 and 1994 (14,438 observations). The second one is drawn from the working age population and is restricted to wage earners (4,628 observations). These two data sets are merged with administrative registers. The author compares the results obtained from two estimations of a wage equation: one based on the overall wage distribution and the second using wages reported by the individuals who exit the unemployment register for employment (post-unemployment wages). Kyyrä finds that the wage differentials between educational level and between men and women are smaller in the post-unemployment wage estimation than in the overall wage estimation. The authors deals also with the importance of financial incentives faced by the unemployed in Finland. These incentives are studied in a cross-sectional framework (in fact, the sample used is of the panel form but is processed by "cross-sectional methodologies"). The wages earned by individuals who leave unemployment for employment are used to predict wages for the whole sample, while the estimated post-unemployment wages are used to compute the expected change in the disposable income of the household that would result from the transition to employment of the unemployed member. Two income ratios are computed: an observed income ratio and an estimated income ratio. Kyyrä finds that 31 per cent of those who move from unemployment into employment record an increase of their household's disposable income less than or equal to 25 per cent. Moreover, 4 per cent of those who leave unemployment for employment accept a job leading to a decrease in their household's disposable income. Concerning the estimated income ratio, 8 per cent of the sample are facing a ratio less than 1 and 43 per cent are estimated to be unable to increase their household's disposable income more than 25 per cent. A large part of the households exposed to a financial trap (observed and estimated) are couples.

The recent study of Pedersen and Smith (2001) analyzes the importance of economic disincentives faced by unemployed and low paid workers in Denmark, using a panel survey merged with administrative registers for the years 1993 and 1996. For this purpose, they compute an individual net income ratio between collecting unemployment benefits and working in a full-time job. This ratio includes some social transfers like housing benefits and child care subsidies 
but also some fixed costs linked to job holding (commuting costs and child care costs). For the individuals unemployed during the week when the interview took place no information is available about the wages and the fixed costs of work. Concerning the wages, the unemployed's own expectations about the wage they would obtain in a future job are used to compute the income ratio. Pedersen and Smith do not develop a predicted wage rate based on an estimated wage equation: the use of the unemployed's own expectations avoids the correction of wages for sample selection bias in a panel framework. The predicted amount of fixed costs of work are obtained through estimations based on data on the employed individuals. For the individuals in employment at the date of the survey, the amounts of unemployment benefits and others social transfers are calculated by using the information included in the administrative registers. The analysis of the replacement ratios shows that 9.1 per cent and 10.9 per cent of the unemployed were in an unemployment trap (net income ratio greater than or equal to 1) in 1993 and in 1996, respectively. Unemployed women are more exposed to financial disincentives than unemployed men; 12.2 per cent and 14.6 per cent of the women were trapped in unemployment in 1993 and 1996, respectively. This proportion is lower for men: 4.9 per cent in 1993 and 6.7 per cent in 1996 . The net income ratios were also computed for people working during the week of the interview. The results for the workers suggest that for 7 per cent and 9.5 per cent of them in 1993 and 1996, respectively, the disposable income in work was lower than the one that would be obtained through receiving unemployment benefits. For the unemployed, the proportion of women facing an unemployment trap is larger than that of men. The panel structure of the data allows the author to look at the transitions that occur between 1993 and 1996 in and out of the unemployment trap state. Pedersen and Smith underline, without distinction between unemployed and employed workers, that 19 per cent of the men and 20 per cent of the woman who were trapped in unemployment in 1993 had not escaped the trap in 1996.

Several empirical studies have examined the earnings losses associated with a period of unemployment (Jacobson et al., 1993; Ruhm, 1991; Stevens, 1997; OECD, 2002; Arulampalam, 2000; Nickell, 1999 ). The general findings from these studies suggest that the cost resulting from job loss is not limited to a loss of earnings in the period of unemployment: unemployed are usually (re)employed at lower wages than the ones they earned in their previous job. Moreover, despite various methodologies and data sets, consistent evidence has been found concerning the persistence of reductions in wages following displacement (see Fallick, 1996 for a survey of the recent empirical literature on displaced workers; see also Kletzer, 1998).

The theory suggests several reasons to explain why a period of unemployment may be followed by wage losses. The first one concerns job tenure: jobs associated with post-unemployment wages are by definition short-tenure at the time at which one observes them (no seniority effect). Lower postunemployment wages may also result from a loss of firm-specific (or sectorspecific) human capital which is not transferable to a new job. A reduction in the post-unemployment wages may also be caused by a lower quality of the job match between the worker and the firm. Further, a decrease in the reservation 
wage over time can lead to acceptance of a job with a lower wage. The decline of the reservation wage can be justified for instance by a (expected) decrease in the level of unemployment benefits, see e.g. van den Berg (1990).

To conclude, three important results should be emphasized on the grounds of the studies mentioned above. First, some transitions from unemployment to employment are associated with a decrease or a small increase of the disposable income. Second, unemployed workers get re-employed at lower wages than the ones they enjoyed in their previous job. Third, the wage losses suffered by workers that have experienced a period of unemployment are persistent; the average wage rate tends to remain below the expected average wage rate without job loss(es) for several years after the unemployment spell(s).

\section{Methodology}

In the study of financial incentives associated with unemployment to employment transitions, one point worth being underlined: the selection into work may be non-random. If not adequately controlled for, sample selectivity is likely to affect the parameters of interest by biasing them. The availability of panel data instead of a single cross-section allows to follow individuals and their behaviour over time, the appropriate estimator in that case is one that exploits the panel structure of the data when correcting for sample selection bias.

In general, two main approaches have been followed in the development of panel data sample selection model estimators: two-step estimators following the idea of Heckman (1979) and maximum likelihood estimators (see the estimators suggested by Wooldridge 1995; Kyriazidou, 1997; Vella and Verbeek, 1999; Rochina-Barrachina, 1999. See also Dustman and Rochina-Barrachina, 2000; Lee, 2001; Hausman and Wise, 1979; Ridder, 1990; Verbeek and Nijman , 1996).

Although one can choose between a random and a fixed approach, when the equation of interest is mainly the wage equation, the random effect approach is to be preferred. In the second approach, time-invariant covariates are absorbed in the fixed effects and their estimates cannot therefore be used to gather insights into the factors associated to higher or lower wages. This point is made particularly clear in Jensen et al. (2001) that survey different panel selection estimators and suggest using a random effects estimator when one is interested in the wage equation estimates. We have adopted this approach in our study. Specifically, we estimate a parametric panel data random effects model. We briefly describe the model below.

The model we consider can be formulated as follows:

$$
\begin{aligned}
y_{i t}^{*} & =x_{i t}^{\prime} \beta+\alpha_{i}+\varepsilon_{i t} \\
d_{i t}^{*} & =z_{i t}^{\prime} \gamma+\eta_{i}+v_{i t} \\
d_{i t} & =1 \text { if } d_{i t}^{*}>0,0 \text { otherwise } \\
y_{i t} & =y_{i t}^{*} \cdot d_{i t},
\end{aligned}
$$


where $i(i=1, \ldots, N)$ denotes the individual and $t(t=1, \ldots, T)$ denotes the time period; $d_{i t}$ is an indicator for having an observed wage, $y_{i t}$ denotes the log of the observed wage, $x_{i t}$ and $z_{i t}$ are vectors of explanatory variables, possibly with common elements. The equation of interest is the first one in (1) and the selection process is described by the second equation in (1). Here, $\beta$ and $\gamma$ are the unknown parameter vectors that we have to estimate. The $\alpha_{i}$ and $\eta_{i}$ are unobservable time-invariant individual-specific components which are possibly correlated with each other and with the explanatory variables; finally $\varepsilon_{i t}$ and $u_{i t}$ are unobserved disturbances (possibly correlated with each other). The variable $y_{i t}^{*}$ is observed only if the indicator variable $d_{i t}=1$. This means that sample selectivity needs being accounted for.

In this estimation procedure the selection process and the equation of interest are estimated simultaneously. For this purpose it is necessary to specify the joint distribution of the error components treated as random effects in the selection equation and the equation of interest. Specifically, we assume that the error terms follow a bivariate normal distribution

$$
\left(\varepsilon_{i t}, v_{i t}\right) \sim N(0, \Sigma), \text { where } \Sigma=\left[\begin{array}{ll}
\sigma_{\varepsilon}^{2} & \rho \sigma_{\varepsilon} \\
\rho \sigma_{\varepsilon} & 1
\end{array}\right]
$$

Thus, the individual-specific effects in the selection equation and the main equation may be correlated, but they are assumed to be uncorrelated with the idiosyncratic error terms. The likelihood of a single observation, conditional on the random effects is then (Jensen et al., 2001)

$$
\begin{aligned}
L_{i t}\left(\psi ; \alpha_{i}, \eta_{i}\right)= & f\left(\varepsilon_{i t}, v_{i t} \mid \alpha_{i}, \eta_{i}, x_{i t}, z_{i t}\right) \\
= & {\left[\int_{-z_{i t}^{\prime} \gamma-\eta_{i}}^{\infty} \phi_{\varepsilon v}\left(y_{i t}-x_{i t} \beta-\alpha_{i}, v_{i t}\right) d v\right]^{d_{i t}} } \\
& \times\left[\int_{-\infty}^{-z_{i t}^{\prime} \gamma-\eta_{i}} \int_{-\infty}^{\infty} \phi_{\varepsilon v}\left(\varepsilon_{i t}, v_{i t}\right) d \varepsilon d v\right]^{1-d_{i t}} \\
= & {\left[\int_{-z_{i t}^{\prime} \gamma-\eta_{i}}^{\infty} \phi_{v \mid \varepsilon}\left(v_{i t} \mid y_{i t}-x_{i t}^{\prime} \beta-\alpha_{i}\right) \cdot \phi_{\varepsilon}\left(y_{i t}-x_{i t}^{\prime} \beta-\alpha_{i}\right) d v\right]^{d_{i t}} } \\
& \times\left[\int_{-\infty}^{-z_{i t}^{\prime} \gamma-\eta_{i}} \phi_{v}(v) d v\right]^{1-d_{i t}} \\
= & {\left[\left(1-\Phi_{v \mid \varepsilon}\left(-z_{i t}^{\prime} \gamma-\eta_{i} \mid y_{i t}-x_{i t}^{\prime} \beta-\alpha_{i}\right)\right) \cdot \phi_{\varepsilon}\left(y_{i t}-x_{i t}^{\prime} \beta-\alpha_{i}\right)\right]^{d_{i t}} } \\
& \times\left[\Phi_{v}\left(-z_{i t}^{\prime} \gamma-\eta_{i}\right)\right]^{1-d_{i t}},
\end{aligned}
$$

where the conditional distribution $v \mid \varepsilon \sim N\left(\frac{\rho \varepsilon}{\sigma_{\varepsilon}},\left(1-\rho^{2}\right)\right) ; \Phi$ and $\phi$ are the standard normal distribution and probability density function respectively for the variables referred by subscripts.

The bivariate random effects are assumed to follow a discrete distribution with $2 \times 2$ points of support and we assume independence between idiosyncratic errors and random effects. 
Let $\alpha=\left\{\alpha_{1}, \alpha_{2}\right\}, \eta=\left\{\eta_{1}, \eta_{2}\right\}, p=\left\{p_{11}, p_{12}, p_{21}, p_{22}\right\}$, where $p_{k j}=$ $\operatorname{Pr}\left[\eta_{k}, \alpha_{j}\right]$, and let $\theta=\left[\beta, \gamma, \sigma_{\varepsilon}, \rho, p, \alpha, \eta\right]$ denote the parameter vector. For a single individual we derived the contribution to the likelihood function as follows:

$$
\begin{aligned}
L_{i}(\theta) & =\int_{-\infty}^{\infty} \int_{-\infty}^{\infty}\left[\prod_{t=1}^{T_{i}} f\left(\varepsilon_{i t}, v_{i t} \mid x_{i t}, z_{i t}, \eta_{i}, \alpha_{i}\right)\right] d G\left(\eta_{i}, \alpha_{i}\right) \\
& =\sum_{j=1}^{2} \sum_{k=1}^{2} p_{k j} \prod_{t=1}^{T_{i}} f\left(\varepsilon_{i t}, v_{i t} \mid x_{i t}, z_{i t}, \eta_{k}, \alpha_{j}\right)
\end{aligned}
$$

where $G(\cdot)$ is the joint CDF of the random effects.

This model is estimated separately for men and women. This allows us to distinguish the expected wages according to gender and to account for phenomena that affect males and females labour market participation differently.

In order to be able to compute the income ratio for each individual in the sample (i.e. also for the individuals that are "fictionally" employed; see Kyyrä, 1999) we compute the expected log wages as in Rosholm et al. (2001).

Conditional on participation in a given year and on the entire path of participation indicators, the expected log wage for an individual is

$$
\begin{aligned}
& E\left[y_{i t} \mid d_{i 1}, \ldots, d_{i T_{i}}, x_{i t}, z_{i 1}, \ldots, z_{i T_{i}}\right] \\
= & x_{i t} \boldsymbol{\beta}+E\left(\alpha_{i} \mid d_{i 1}, \ldots, d_{i T_{i}}, z_{i 1}, \ldots, z_{i T_{i}}\right)+E\left(\varepsilon_{i t} \mid d_{i t}, z_{i t}\right)
\end{aligned}
$$

The expected values of the error components of the wage equation are

$$
\begin{aligned}
E\left(\alpha_{i} \mid d_{i 1}, \ldots, d_{i T_{i}}, z_{i 1}, \ldots, z_{i T_{i}}\right) & =\sum_{j=1}^{2} \alpha_{j} q_{j i}^{\alpha} \\
E\left(\varepsilon_{i t} \mid d_{i t}=1, z_{i t}\right) & =\rho \sigma_{\varepsilon} \sum_{k=1}^{2} q_{k i t}^{\eta} \frac{\phi\left(z_{i t} \gamma+\eta_{k}\right)}{\Phi\left(z_{i t} \gamma+\eta_{k}\right)} \\
E\left(\varepsilon_{i t} \mid d_{i t}=0, z_{i t}\right) & =-\rho \sigma_{\varepsilon} \sum_{k=1}^{2} q_{k i t}^{\eta} \frac{\phi\left(z_{i t} \gamma+\eta_{k}\right)}{1-\Phi\left(z_{i t} \gamma+\eta_{k}\right)}
\end{aligned}
$$

with $\rho$ and $\sigma_{\varepsilon}$ defined above.

The term $q_{j i}^{\alpha}$ denotes the parameters of the individual specific probabilities of $\alpha_{i}$. Its expression is

$$
q_{j i}^{\alpha}=\frac{\sum_{k=1}^{2} p_{k j} \prod_{t=1}^{T_{i}}\left[\Phi\left(z_{i t} \gamma+\eta_{k}\right)^{d_{i t}}\left[1-\Phi\left(z_{i t} \gamma+\eta_{k}\right)\right]\right]^{1-d_{i t}}}{\sum_{l=1}^{2}\left[\left(p_{l 1}+p_{l 2}\right) \prod_{t=1}^{T_{i}}\left[\Phi\left(z_{i t} \gamma+\eta_{l}\right)^{d_{i t}}\left[1-\Phi\left(z_{i t} \gamma+\eta_{l}\right)\right]\right]^{1-d_{i t}}\right]}
$$

and $q_{k i t}^{\eta}$ denotes the parameters of the individual and time specific probability of $\eta_{i}$ (see Rosholm et al., 2001)

$$
q_{k i t}^{\eta}=\frac{\sum_{j=1}^{2} p_{k j} \Phi\left(z_{i t} \gamma+\eta_{k}\right)}{\sum_{j=1}^{2}\left[\left(p_{1 j} \Phi\left(z_{i t} \gamma+\eta_{1}\right)+p_{2 j} \Phi\left(z_{i t} \gamma+\eta_{2}\right)^{1-d_{i t}}\right]\right.}
$$




\section{Data}

\subsection{The sample}

The empirical analysis is based on the Panel Study of Belgian Households (PSBH). This survey was carried out for the first time in the spring of 1992 (wave 1) and contains a variety of information. We have decided to consider the waves 3 to 7 (spring 1994 to spring 1998) because both the questions concerning the income and the definition of employment have been modified from 1994 onwards. Since the information we use is retrospective, the analysis covers the years 1993 to 1997 . The waves 3 to 7 contains information about 9,398 individuals aged at least 16 . The sample is unbalanced, since individuals are observed from one to seven times.

At each survey date, individuals report their labour market status at the time of the interview and for each of the preceding twelve months. At the same time people are interviewed about their annual income for the previous year net of taxes and social contributions.

Among the 9,398 individuals interviewed during the waves retained for the analyses, 1,338 have known at least one unemployment spell during the observation period. We observe 1,948 unemployment spells, however we focus only on those that are "subsidized". For this reason we consider 1,661 unemployment spells, experienced by 1,142 individuals. Half of the unemployment spells end with a transition towards employment (paid work and self-employment); 12 per cent of the unemployment spells end with a transition towards the "nonparticipation" state (retirement, housekeepers and students); 35 per cent of the unemployment spells are right-censored and 3 per cent of the unemployment spells end in a so-called "other activity". Regarding the spells of unemployment which are right-censored, 67 per cent concern individuals who remain unemployed at the end of the observation period and 33 per cent are due to panel attrition.

The sample used in this study is made of both unemployed individuals (men and women) having moved towards employment (working at least 15 hours per week) and unemployed persons who remain unemployed throughout the whole survey period. Individuals who moved from unemployment into selfemployment have been excluded from the analysis. The reason for discarding those individuals resides mainly in the fact that in Belgium there is a large number of people reporting false self-employment status (paying for this social security contributions) but receiving a monthly salary from their employer. In addition, for them it is difficult to distinguish the wages from the profits.

After having discarded these observations, our sample consists of 1,341 spells of compensated unemployment, experienced by 959 individuals. We will use separate samples for men (601 spells) and women (740 spells).

\subsection{The dependent variables}

The dependent variables are an employment indicator stating whether the individual has moved into employment and the individual's monthly net wage. 
The employment indicator takes a value of 1 if the individual moves from compensated unemployment to paid work during the observation period. To be considered as employed in the PSBH, people have to work at least 15 hours per week. The information available in the survey concerning hours of work are about hours as specified in the job-contract and hours actually worked. We have chosen the last definition since labour income covers also extra-hours worked.

The dependent variable of the wage equation is the monthly net wage including tips, commissions, bonus and holiday earnings. At each survey date, and therefore yearly, the interviewed individuals report the amount of the wages net of taxes and social contributions. For each of the five waves, we use the number of months in which the individual is unemployed or employed to compute the monthly in-work and out-of-work income. Monthly wages are then computed by dividing annual salaries by the number of months worked. However, computing monthly wages from the annual income information does not allow to separate the wages associated with different jobs in the case where the worker has been employed in more than one job for the same year. ${ }^{3}$ The wage is deflated by the consumer price index (base 1997). For 25 per cent of the unemployment spells which ended into work, the information concerning the wages is missing. We take care of this in the estimation procedure. The introduction of the log monthly wage is justified here in the context of labour supply theory (see D'Addio and De Greef, 2001).

\subsection{The explanatory variables}

Various explanatory variables have been introduced in the estimated models. Broadly speaking only work-related variables (i.e. experience and its square, educational attainments, a part-time indicator, a supervision-tasks indicator, an indicator of previous professional experience) have been introduced in the wage equation. In order to capture the effects of financial (and to some extent of non-financial) incentives, many other variables appear in the selection equation.

Tables 2 and 3 in the Appendix present descriptive statistics of the sample. A distinction is made between the spells which end with a transition to employment (spells ' $E$ ' for employment) and those of unemployment for the whole survey period (spells 'U' for unemployment).

[Table 2 and 3 to be inserted here]

We start with the description of the variables used in the wage equation.

Experience refers to "potential" work experience and it is computed as the difference between the age at the survey date and the age when the individual left school. For this variable, we also introduced a quadratic form to capture concavity in the experience-wage profiles as postulated in human capital theory. A variable indicates also whether the individual had a professional experience in the past; it could pick up the returns to accumulated general human capital. Further, to capture the level of responsibility associated with previous

${ }^{3}$ The same methodology is applied for unemployment benefits. 
job-experience we have introduced an indicator taking on the value 1 if the individual has never supervised other workers in the past.

In order to capture the "scarring" effect linked to the experience of previous long unemployment spells on subsequent earnings, we have included in the specification an indicator for the experience of long term unemployment (if the individual has been unemployed for more than twelve months at the start of the year).

We have used an indicator for part-time that seems to be a striking feature in female labour market participation. Indeed the available information on hours worked suggests that for women 31.5 per cent of the transitions from unemployment into employment are made in the form of part-time jobs. Furthermore, women work on average 34 hours per week. Conversely, for men the majority of transitions from unemployment into employment is made of full-time jobs: only 7 per cent of the transitions from unemployment into employment are made of part-time jobs. The average number of hours worked per week is for men equal to 41.4. This part-time indicator has been built using the information on the hours of work reported in the survey. Specifically, part-time arises when the number of hours worked per week is less than thirty. Full-time is defined accordingly. The distinction between full-time and parttime work is not possible for all the sampled members because of the structure of the survey; the information on the hours worked are given at the time of the interview (spring) but if the transition from unemployment to employment occurs between the two interrogations and the individual is unemployed at the date of the first and second interview we have no information about the hours. In addition, a proportion of those in work at the date of the interview do not report the hours worked. In fact, for 74 per cent of our sample, we know if the unemployed left unemployment for full-time or part-time work.

Education is introduced in our specification through a set of indicators for the highest level of formal education attained. Five educational levels are considered; primary school or without education the reference), lower secondary school (3 years after primary school), upper secondary school (6 years after primary school), high school (2 to 4 years after the secondary school) and university.

Other variables commonly thought to have an effect on wages such as type of job, sector of the firm, firm size and union coverage have not been introduced mainly owing to the lack of information about them in the available dataset. Further, the limited number of observations has prevented us for using annual dummy variables in the regressions.

Besides the individual's age and its square, educational attainments and the long-term unemployment indicator several variables have been introduced in the selection equation.

Two variables account for the health of the individuals. While the first states their degree of physical health, the second refers to individuals' mental distress.

According to the former, unhealthy individuals are those that have described themselves as having a health problem, like for instance suffering from a chronic illness or from a handicap, being an invalid, and if they have spent more than 
14 nights in hospital for the previous year (except for childbirth).

The variable reporting mental distress has been built (see Sweeney, 1998) in the following way. We have computed a score for each individual by attributing one point each time the individual answered "always" or "nearly always" to the next questions: "To which extent have you experienced each of the 17 negative feelings during the three months prior to the interview?". The feelings are: feeling tired, having physical symptoms, feeling bad, being irritable, need of being comforted, having strange thoughts, being pessimistic, crying easily, thinking about death, thinking about suicide, unable to concentrate, having unpleasant thoughts, feeling guilty, unable to sit quietly, having insomnia, losing weight or appetite, feeling depressed. The average distribution of scores for the sample follows: 47 per cent has score equal to zero, 18 per cent has score equal to one and 11 per cent has score equal to two. In addition, for 15 per cent of the sample the score is at least of 4 points. Individuals whose score are higher than fours points are classified as "suffering from high mental distress".

A measure of social involvement (see Sweeney, 1998) has been built in order to differentiate people socially active from the others. Individuals are ranked as socially active if there are member of an association as a sport club, a cultural or a humanitarian association or if they have a very active circle of friends.

To measure the effect of some other kinds of financial support received when unemployed, a dummy variable has been introduced. It takes the value of one if the unemployed or his household is receiving a financial support from the state e.g. social housing with low rent or food-stamps.

Three variables related to pecuniary difficulties have been used in the model. First, a dummy indicates if the individual, or another member of his/her household, is in debt (excepting for a mortgage loan). A second dummy takes the value of one if the unemployed has any financial difficulties concerning the paying of bills related to e.g. rent, heating. The third dummy is equal to one if the unemployed is unsatisfied about his financial situation. The last variable is subjective, the first two are more objective.

Another variable reports whether the individual owns or rents the accomodation he/she is living in. It takes the value of one for owners.

Some of the variables account for the household composition. They are the number of children, the presence of children aged less than three (capturing effect linked to child care costs), being married, being a lone parent ${ }^{4}$, not being the head of the household, being entitled to additional child benefits.

The variable concerning the nationality is restricted to Belgian or non Belgian.

Finally, owing to the peculiar structure of Belgium, made of three regions (Brussels, Wallonia and Flanders) and since one of them presents lower unemployment problems, we have introduced a dummy stating whether the individual lives there (Flanders).

\footnotetext{
${ }^{4}$ The information about the type of family could be misleading for the unemployed who live with their parents because they are classified as member of a couple.
} 


\section{Estimation results}

\subsection{Wage and Selection equation}

The results derived from the estimation of (1) on the samples of men and women separately are reported in Tables 4, 5, 6. In discussing them, we keep in mind that one of the main purposes of this study is to investigate whether unemployment traps exist and they significantly affect the behaviour of individuals moving into employment.

[Table 4, 5, 6 to be inserted here]

In this respect, the results derived from the estimation of the wage equation corrected for sample selectivity in a panel data framework can lead to some interesting hints about the randomness or non-randomness of the selection process into work. In order to gather these additional pieces of information, we estimated also the selection equation and the wage equation separately by standard panel data techniques ignoring therefore the correlation between the two process. Specifically, we have estimated the selection equation by using a probit random effect model and the wage equation as a linear equation model with random effects. The estimates obtained are reported in Tables 7, 8, 9 and 10 (see below).

Looking at the results obtained through estimation of (1) simultaneously by Maximum Likelihood we first notice that some significant differences in the behaviour of males and females appear. Moreover sample selectivity seems to affect more women than men. This issue is discussed further below.

Considering the results of the selection equation for women, we notice that the most significant parameter is the one associated with previous unemployment status: women having experienced long-term unemployment, are likely to participate less on the labour market. Furthermore, married women participate more; conversely those that are not heads of the household have difficulties in moving into employment. Surprisingly, none of the variables linked to the presence of children seem to affect women's participation decisions except for the variable accounting for entitlement to additional child benefits when being the head of the household. The sign and the fact that this coefficient is statistically significant seems to suggest that women that are heads of the household and benefit of additional child benefits participate less. The information of child care costs would certainly allow us to interpret better this effect; unluckily it is not available. Still for women, higher educational attainments are associated with better earnings prospects.

Different factors seem to affect men's participation decision. Similarly to women, the experience of long term unemployment shows up in higher difficulties in (re)integrating the labour market. For this sub-sample we observe that health matters, since having had some "physical" health problem affects significantly their participation decisions by lowering the probability of finding a job. Differently from women, the fact of receiving additional child benefits for the heads of the household do not affect in a significant way the propensity to participate in the labour market. It is the status in the household that matters 
for men: when they are not heads of the household they participate less. The same negative effect is associated with the presence of many children in the household.

Another interesting difference between men and women is the effect related to educational attainments: while for women the highest education levels are associated to the best outcomes on the labour market, for men it is upper secondary school that provides the best chances.

Let us turn now to the wage equation results. Again for both sub-samples, the experience of long-term unemployment in the past has a significant negative effect on earnings' prospects, through lowering the wage level when employed. Similar results have been proposed in Gregory and Jukes (1997) and Nickell (1999) that point at the fact that in Great Britain, long unemployment spells are associated with greater wage losses, while the study of Arulampalam (2000) doesn't find any significant effect linked to the duration of the previous unemployment spells. However that result is likely to be linked to the specific unemployment variable used in her study. As to the educational attainments we notice the totally different results for the two samples considered. While for women, the best earnings prospects are associated with the highest educational attainments, for men this happens at the lowest educational levels. The indicator coefficients associated with educational attainments can be interpreted as estimates for the relative earnings advantages of persons who have acquired different levels of education over workers who have completed only the basic level. In this respect, the advantage of holding a university degree for women seems to be very high. Women having exerted some supervision tasks in the past have also comparative advantage over those whose previous work experience didn't present this feature. This result can be justified by thinking that supervision tasks are associated frequently to more important jobs.

As to the variable referring to the years of potential work experience, its significant positive coefficient, for both the samples considered, reveals that previous experience improve considerable the earnings prospects of unemployed individuals. As suggested by the human capital theory, the quadratic term of work experience confirms concave experience-wage profiles for both samples.

Unluckily none of the variables being linked in some way to non-financial incentives (like participation in social activity) turns out to be significant for the two samples analysed.

Let us turn now to the problem of sample selection. We notice from table 6 that the correlation coefficient is significantly different from 0 and positive only for women. For them, the probability associated with the support points in either the wage and the selection equation are significant, while for men they are not. This suggests that the process of moving into work is for women non random. The significant correlation coefficient and its positive sign is consistent with good economic sense: those who find wage offers relatively high with respect to their characteristics, are more likely to be hired (see Kyyrä, 1999).

These findings are confirmed by the comparison of the coefficients of the wage equation and the selection equation obtained through the estimation of model (1) simultaneously and separately, ignoring in this case, the sample selection bias (see tables 7, 8, 9 and 10). 
[Table 7, 8, 9 and 10 to be inserted here]

In general, the effects resulting from the estimation of the simplest specifications are of low magnitude. It is however worthwhile noticing that the simplest specifications would produce the same kind of estimates of the parameter of interests, though still biased due to the omission of sample selection. However, while for men (see tables 7 and 8), the results in the two specifications tend to be very similar, for women (tables 9 and 10) we can notice significant differences in the magnitude of some interesting parameters, especially in the wage equation. Specifically, the effect of experience is not captured in the simplest specification, and the influence of long-term unemployment turns out to be much weaker there.

It is therefore likely, that owing to higher male participation in the labour market, sample selectivity plays only a marginal role for this population, while for women the transition into employment seems to be more selective.

To summarize the overall results, we notice that previous long term unemployment experience has a negative and significant impact for the two samples considered: on one hand, it is likely to reduce individuals' propensity to move into employment, and on the other hand when individuals choose to get back to work, it lowers the earnings prospects. The general belief about the depreciation of human capital during a spell of unemployment and the fact that the longer the interruption more the decline is confirmed in our study: long-term unemployment is likely to have a scarring effect on subsequent earnings (see Arulampalam, 2000).

The results suggest also that more experienced workers are conversely more likely to earn higher wages and that workers holding higher qualification levels perform better in terms of their earnings prospects compared to those holding only a basic educational level.

Let turn now to the discussion of the results concerning the presence of unemployment traps.

\subsection{Estimated and observed income ratios}

In order to evaluate whether unemployment traps exist and are significant in the transition from unemployment to employment for Belgian unemployed individuals present in the PSBH for the years 1993-1997, we have computed three different income ratios in the spirit of Kyyrä (1999).

The key tool in computing these different ratios is the wage. However for some observations in the sample the wage is missing either because the individuals have been unemployed for the whole survey period (i.e. those that we will consider in the following as "fictionally" employed) or because they didn't report the wage at the date of the interview. In order to compute the ratios for the individuals either whether they move into employment or whether they don't move into that state, we have used the expected wage predicted on the grounds of the estimates of the wage equations as illustrated in expression (2) in section (4). In addition, for the sample of individuals making the transition into employment, the observed wage is available. 
In Table 11we present the mean of the different wages used in the computation of the income ratios for all the sampled individuals and for those "fictionally" employed distinguishing them by gender. It is worthwhile noticing that in addition to the mean observed wages $(O W)$, two different mean expected wages are reported: the former $\left(E W_{-} 1\right)$ is computed by imputing to each sample member the expected wage while the latter $\left(E W \_2\right)$ is obtained by imputing the expected wage only to those individuals that have missing wages owing either to the fact that they have not left the unemployment state for the whole survey period or to the fact that they haven't reported the amount of the wage when interviewed. For those individuals that do not move into work it is clear that $E W \_1=E W \_2$.

[Table 11 to be inserted here]

The mean predicted wage is very similar to the mean observed one. Significant differences arise between men and women. As a matter of fact, the wages earned by women are considerably lower compared to those of men.

As said above, we have computed three different income ratios where, from a general point of view, the numerator is the individuals' disposable income when employed (obtained by summing up the wages and other non-related work incomes, $N W I$ ) and the denominator is represented by the individuals' disposable income when unemployed (derived by summing up the unemployment benefits, $U B$, and other non-work related incomes, $N W I$ ). Concerning the denominator, some observations are characterized by missing values for unemployment benefits. This forced us to estimate the amount of unemployment benefits associated with those spells. As mentioned in section 2, the level of the unemployment benefits to which the unemployed is entitled depends on four elements: the age, the unemployment duration, the type of family and the previous wage. The estimation that we use is based on the first three elements since the information concerning the wage earned in the last job prior to employment is not available. Therefore, when the information about the unemployment benefits is missing, we decide to impute the maximum and the minimum unemployment benefit.

The ratios computed are: (1) an observed income ratio $(O I R) ;(2)$ an estimated income ratio $\left(E I R_{-} 1\right)$; and finally (3) a combination of both of them $\left(E I R \_2\right)$.

The first ratio can only be computed for the individuals that move into jobs during the observation period. It writes as

$$
O I R=\frac{N W I+O W}{N W I+U B}
$$

The second one writes as

$$
E I R_{-} 1=\frac{N W I+E W \_1}{N W I+U B}
$$

The third one is a combination of the previous two ratios. Indeed in this case we impute the estimated (expected) wages only to those individuals that have 
not made the transition towards employment during the observation period. To the others, we impute the observed income. It writes as

$$
E I R \_2=\frac{N W I+E W \_2}{N W I+U B}
$$

Since disposable income is likely to vary with the household composition, we have classified the households in five categories. The idea behind this distinction is to consider households with children or without children depending on the presence of at least one child aged less than 6 in the household. On this grounds we have distinguished among: (1) singles, i.e. those living on their own; (2) Couples, i.e. those living with a partner and without children aged less than six; (3) Couples with children, i.e. those living with a partner and having at least one child aged less than six; (4) single parents, i.e. individuals living alone and possibly with children aged more than six; (5) Single parents, i.e. individuals living without a partner and having at least one child aged less than six.

The presence of unemployment traps is revealed in this framework by a ratio smaller than 1 . When the ratio equals 1 individuals are likely to be indifferent between working and not working. Whereas when the ratio is higher than 1 they should have an incentive to move into work.

We have summarized the results obtained when each of the previous ratios is smaller or equal to 1 in tables 12, 13 and 14 for the entire sample.

[Table 12, 13 and 14 to be inserted here]

From table 12 reporting the ratio lower or equal to 1 for those that move into employment, we notice that $3.31 \%$ of men and $9 \%$ of women accepts employment when this is associated with a reduction in their disposable income. While the same magnitude is revealed by the comparison between men and women according to the household's composition, we remark that $13 \%$ of women having experienced long-term unemployment in the past accepts a reduction in their disposable income when moving to employment. It is also interesting to notice from Figure 1 that almost $20 \%$ of the employed women accepts either this reduction or only a slight increase in their disposable income. For men, the phenomenon is less important, however also for almost $13 \%$ of them the transition into work presents the same feature (see Figures 2, 3, 4, 5, 6, 7 and $8)$.

[Figures 1, 2, 3, 4, 5, 6, 7 and 8 to be inserted here]

When considering tables 13 and 14 reporting the estimated income ratios for all the individuals in the sample the same comments apply. We remark nevertheless that almost $22 \%$ of women would be trapped in the unemployment state and this situation is strengthened for single mothers with children aged less than six (49\%) and for those having experienced a long unemployment spell in the past.

In table 15 we report the mean of both the observed and estimated income ratios for the individuals moving into jobs during the observation period. We 
derive as a conclusion that the estimated income ratios are in general slightly lower than the observed ones. It is interesting to notice is that for women the rewards associated to the transition into employment are considerably lower compared to those obtained by men.

[Table 15 to be inserted here]

There are several ways to explain why it may be meaningful in some cases to accept a job associated with negative short-term financial returns. Such behaviors could be justified for instance by the fact that the unemployed give a very large importance to the intertemporal perspectives: they are likely to expect higher wages in the future (promising career prospects) or lower the negative effect of long unemployment periods. Some individuals may even be willing to accept a job that is associated with long-term income losses if they enjoy working or if they simply "feel ashamed to be unemployed".

In table 16 we summarize the results for those having not moved into employment during the survey period, i.e. the so-called fictionally employed (see also Figures 9 and 10).

[Table 16 to be inserted here]

[Figures 9 and 10 to be inserted here]

We remark for those individuals that $5.46 \%$ of the men and $28 \%$ of women would have no incentive to move into work since this transition would be associated with a considerable reduction in the disposable income. Single men $(8.33 \%)$, and couples with children (13\%) are those more exposed to the risk of these traps. For women, the striking results associated with the experience of long-term unemployment in the past confirms once again the great importance of the past history on the labour market for this population. Women in this situation are very likely to have no incentives to accepts jobs since the wages they would earn will be lowered by the negative influence of their previous carrier paths (see Fig. 11 and 12).

[Figures 11 and 12 to be inserted here]

\section{Conclusion}

In this paper we investigated whether unemployment traps exist and are significant for Belgian individuals. In order to assess them we have used panel data sample selection models. Specifically we adopted a parametric random effects model specification composed by a wage equation and a selection equation that has been estimated simultaneously by maximum likelihoods techniques. The income ratios useful to determine the presence of financial traps have been computed for every individual in the sample by using the predicted wages obtained from the estimation of the wage equation corrected for sample selectivity.

The empirical analyses has exploited the data extracted from the waves 1993-1997 of the Panel Study of Belgian Household and has been led separately 
on (unbalanced) samples of men and women. The estimation results suggest significant differences in the behaviour of these two groups. A common striking factor affecting both the level of the wages and the participation decisions is represented by the experience of long periods of unemployment in the past: long-term unemployed people seem to have higher difficulties in (re-)integrating the labour market and they obtain lower salaries when they succeed in doing it. Still, more experienced workers have the best earning prospects on the labour market. Finally, high educated women participate more and earn more compared to those holding a basic educational level. However, it should be noticed that the wages offered to women are always lower than those offered to men, ceteris paribus.

The problem of sample selection seems to be particularly important for women, suggesting that, for this population, the transition into work is highly selective.

The computation of the observed income ratio suggests that a high proportion of the transitions into work are associated with important financial losses. However, this phenomenon is particularly striking for women. This finding is confirmed by the results of the estimated income ratio either for all the individuals present in the sample and for those "fictionally" employed. Especially for them, our analysis shows that a high proportion (6\% of men and $28 \%$ of women) are "trapped" financially in the unemployment state since the their transition into work would be accompanied by a substantial reduction in their disposable income. This is particularly true for couples with children aged less than 6. Further, the fact of having had a long-term unemployment experience in the past worsens the picture: almost $31 \%$ of the women and $7 \%$ of the men fictionally employed having experienced long-term unemployment prior to the survey period are likely not to have incentives to accept jobs.

The results of our analysis suggest different considerations. First, since longterm unemployment significantly (and negatively) affects both the earnings and the participation decisions, policies oriented in preventing people from becoming long-term unemployed could have as a consequence an improvement in the incentive these people have to enter the labour market and eventually to lower unemployment itself. Second, since experience matters significantly, it would be possible to increase the propensity of people to participate in the labour market by making them more experienced even through temporary jobs that interrupting the duration of unemployment and allowing to accumulate general human capital would result in an improvement in their present situation. Finally, the fact that women are granted lower wages on the labour market and are those more at risk to be "trapped" in the unemployment state, is very important for policy concerns. Increasing the participation of women to the labour market through the design of some incentives schemes (like those linked to child care) could indeed contribute to lowering the overall unemployment rate and by there alleviate their labour market problems. 


\section{References}

[1] Arulampalam, W. (2000), "Is Unemployment Really Scarring? Effects of Unemployment Experiences on Wages", IZA Discussion Paper n. 189

[2] Atkinson, A. B. and Micklewright, J. (1991), "Unemployment Compensation and Labour Market Transitions: A Critical Review", Journal of Economic Literature, 29, 1679-1727.

[3] Atkinson, A.B. and Morgensen, G. (1993), Welfare and work incentives: A North European perspective, Oxford: Clarendon Press.

[4] Blundell, R. (2000), "Work incentives and 'in-work' benefit reforms: a Review", Oxford Review of Economic Policy, 16 (1), 27-44.

[5] D'Addio, A.C. and De Greef, I. (2001), "Un modèle d'offre de travail pour l'étude des incitants financiers liés à la transition chômage-emploi pour la Belgique", mimeo IRES, Université Catholique de Louvain.

[6] De Greef, I. (2000), "Les pièges financiers en Belgique. Aperçu de la législation du chômage, des spécificités institutionnelles et études de cas types", Revue belge de sécurité sociale, Juin, Bruxelles.

[7] Defeyt, P. (1998), Lutter contre les pièges financiers. Analyse et propositions, Institut pour un développement durable.

[8] De Lathouwer, L., Bogaerts, K. (2001), Financiële incentieven en laagbetaald werk. De impact van hervormingen in de sociale zekerheid en de fiscaliteit op de werkloosheidsval in België, CSB-Berichten, Antwerpen.

[9] De Lathouwer, L. (2000), Les pièges à l'emploi en Belgique: diagnostic et options politiques, CSB-Berichten, Antwerpen.

[10] Duncan, A., Gilles, C. (1996), "Labour supply incentives and recent family credit reforms", Economic Journal, Vol. 106(434), 142-55.

[11] Dustmann, C., and M. E. Rochina-Barrachina, (2000), "Selection Correction in Panel Data Models: An Application to Labour Supply and Wages", IZA Discussion Paper 162, IZA-Bonn

[12] Fallick, B. C. (1996), "A review of the recent empirical literature on displaced workers", Industrial and Labour Relations Review, October.

[13] Gregg, P, Johnson, P. and Reed, H. (1999), Entering Work and the British Tax and Benefit System, Institute for Fiscal Studies, London.

[14] Hausman, J.A., and D.A. Wise, 1979, Attrition Bias in Experimental and Panel Data: The Gary Income Maintenance Experiment, Econometrica 47, 455-473.

[15] Gregory, M. and Jukes, R. (1997), "The Effects of unemployment on subsequent earnings: A study of British men 1984-1994", The Labour Market Consequence of Technical and Structural Change, CEPR DP n. 21 
[16] Heckman, J., 1979, Sample selection bias as a specification error, Econometrica 47, 153-161

[17] Holm, P., Kyyra, T., Rantala, J. (1999), "Household Economic Incentives, the Unemployment Trap and the Probability of Finding a Job", International-Tax-and-Public-Finance, 6(3), 361-78.

[18] Jacobson, L. S., LaLonde, R. J. and Sullivan, D. G. (1993), "Earnings Losses of Displaced Workers", American Economic Review, 83, 685-709.

[19] Jensen, P., Rosholm, and M., M. Verner (2001), "A Comparison of Different Estimators for Panel Data Sample Selction Models", Working Paper

[20] Kyriazidou, E., (1997), "Estimation of a panel data sample selection model", Econometrica 65, 1335-1364.

[21] Kyyrä, T. (1999), Post-unemployment Wages and Economic Incentives to Exit from Unemployment, nro 56, Valtion taloudellinen tutkimuskeskus Research Report, Helsinki.

[22] Kletzer, L. G. (1998), "Job Displacement", The Journal of Economic Perspectives, Volume 12, pp. 115-136.

[23] Laurent, S. (2001), "Capital humain, emploi et salaire en Belgique et ses régions", Quatorzième Congrès des Economistes Belges de Langue Française, Liège.

[24] Layard, R., Nickel, S. and Jackman, R. (1991), Unemployment, macroeconomic performance and the labour market, Oxford University Press.

[25] Lee, M.-J., (2001), "First-difference estimator for panel censored-selection models", Economics Letters 70, 43-49.Ministère fédéral de l'emploi et du travail (1998), Conseil supérieur de l'emploi, Avis nro 4 concernant les pièges à l'emploi, Bruxelles.

[26] Nickell, S.J., Jones,T and Quintini, G. (1999), "A picture of the job insecurity facing British men", CEPR Discussion Paper n. 42, The Labour Market Consequence of Technical and Structural Change

[27] OECD (1996), Employment Outlook, Paris.

[28] OECD (1997), Employment Outlook, Paris.

[29] OECD (1999), Benefit Systems and Work Incentives, Paris.

[30] OECD (2002), Income changes when moving in and out of work, Social policy Division, forthcoming.

[31] Pedersen, P.J., Westergard-Nielsen, N. (1993), "Unemployment: a review of the evidence from panel data", OECD Economic Studies, 20: 65-95.

[32] Pedersen and Smith, P. (2001), Unemployment Traps: Do Financial DisIncentives Matter?, IZA Discussion Paper nro 274. 
[33] Ridder, G., (1990), "Attrition in Multi-Wave Panel Data", in: J. Hartog, G. Ridder, and J. Theeuwes, eds., Panel Data and Labor Market Studies, Elsevier Science Publishers B.V., Amsterdam).

[34] Rochina-Barrachina, M. E., (1999), "A new Estimator for Panel Data Sample Selection Models", Annales d'Économie et de Statistique 55/56, 153181.

[35] Rosholm, M. H. S. Nielsen, and N. Smith,Husted, L., (2001), "Qualifications, Discrimination, or Assimilation? An Extended Framework for Analysing Immigrant Wage Gaps", IZA Discussion Paper n. 365,

[36] Ruhm, C. (1991), "Are Workers Permanently Scarred by Job Displacements?", American Economic Review, Volume 81, 319-324.

[37] Saunders, P., Bradbury, B., Whiteford, P. (1989), "Unemployment Benefit Replacement Rates", Australian Bulletin of Labour, Vol. 15(3), 223-44.

[38] Stevens, A. H. (1997), "Persistent Effects of Job Displacement: the Importance of Multiple Job Losses", Journal of Labour Economics, 15, 165-188.

[39] Schoeni, R., Dardia, M. (1996), "Wage Losses of Displaced Workers in the 1990's", RAND Corporation Report: DRU/1474/RC.

[40] Sweeny, J. (1998), Why hold a job? The labour market choice of the low skilled. Leuven: Katholieke Universisteit Leuven, 263 p.

[41] Vella, F., (1998), "Estimating Models with Sample Selection Bias: A Survey", Journal of Human Resources 33, 127-169.

[42] Vella, F., and M. Verbeek, (1999), "Two-step estimation of panel data models with censored endogenous variables and selection bias", Journal of Econometrics 90, 239-263.

[43] Verbeek, M., and T. Nijman, (1996), "Incomplete Panels and Selection Bias", in: L. Mátyás and P. Sevestre, eds., The Econometrics of Panel Data, Klüwer Academic Publishers, New York.

[44] Wooldridge, J. M., (1995), "Selection Corrections for Panel Data Models under Conditional Mean Independence Assumptions", Journal of Econometrics 68, 115-132. 


\section{Appendix : Tables and Figures}

\subsection{Tables}

Table 1: Belgian tax rates - 1997

\begin{tabular}{l|c}
\hline Annual earnings in euros & Marginal income tax rate in percent \\
\hline $0-6,271.7$ & 25.0 \\
$6,271.7-8,304.4$ & 30.0 \\
$8,304.4-11,849.3$ & 40.0 \\
$11,849.3-27,268.3$ & 45.0 \\
$27,268.3-40,902.4$ & 50.0 \\
$40,902.4-59,990.2$ & 52.5 \\
$\geq 59,990.2$ & 55.0 \\
\hline
\end{tabular}


Table 2: Descriptive Statistics -Men

\begin{tabular}{|c|c|c|c|c|c|c|}
\hline & \multicolumn{2}{|c|}{ Spells 'E' } & \multicolumn{2}{|c|}{ Spells 'U' } & \multicolumn{2}{|c|}{ Spells 'E'+'U' } \\
\hline Number of observations & \multicolumn{2}{|c|}{363} & \multicolumn{2}{|c|}{238} & \multicolumn{2}{|c|}{601} \\
\hline Continuous variables & Mean & St. Dev. & Mean & St. Dev. & Mean & St. Dev. \\
\hline Age & 31.7 & 8.8 & 39.1 & 12.9 & 34.6 & 11.2 \\
\hline Experience & 16. & 12.5 & 21.3 & 13.9 & 16.0 & 12.5 \\
\hline Children & 0.5 & 0.9 & 0.7 & 1.2 & 0.6 & 1.0 \\
\hline Du mmies & \multicolumn{2}{|c|}{ Frequence } & \multicolumn{2}{|c|}{ Frequence } & \multicolumn{2}{|c|}{ Frequence } \\
\hline \multicolumn{7}{|l|}{ Educational dummies } \\
\hline Primary school or no education & \multicolumn{2}{|l|}{9.4} & \multicolumn{2}{|l|}{25.6} & \multicolumn{2}{|l|}{15.8} \\
\hline Lower secondary school & \multicolumn{2}{|l|}{27.8} & \multicolumn{2}{|l|}{32.4} & \multicolumn{2}{|l|}{29.6} \\
\hline Upper secondary school & \multicolumn{2}{|l|}{36.6} & \multicolumn{2}{|l|}{25.2} & \multicolumn{2}{|l|}{32.1} \\
\hline High school & \multicolumn{2}{|l|}{16.3} & \multicolumn{2}{|l|}{10.1} & \multicolumn{2}{|l|}{13.8} \\
\hline University & 9.9 & & 6.7 & & 8.7 & \\
\hline Household dummies & & & & & & \\
\hline Children under 3 years & 10.7 & & 8.8 & & 10.0 & \\
\hline Not head of household & 48.5 & & 76.0 & & 59.4 & \\
\hline Married & 40.2 & & 48.5 & & 43.5 & \\
\hline Not married & 52.3 & & 37.6 & & 46.5 & \\
\hline Divorced, separated or widowed & 7.5 & & 13.9 & & 10.0 & \\
\hline Single & 9.1 & & 15.1 & & 11.5 & \\
\hline Couple & 82.1 & & 81.9 & & 82.0 & \\
\hline Single - parent & 8.8 & & 3.0 & & 6.5 & \\
\hline Additio nal child benefits & 2.7 & & 5.0 & & 3.7 & \\
\hline Regional membership dummies & & & & & & \\
\hline Brussels & 11.8 & & 12.2 & & 12.0 & \\
\hline Wallonia & 55.1 & & 54.6 & & 54.9 & \\
\hline Flanders & 33.1 & & 33.2 & & 33.1 & \\
\hline Job attributes dummies & & & & & & \\
\hline Part -time & 5.5 & & & & & \\
\hline No responsability & 83.7 & & 94.1 & & 87.9 & \\
\hline Previous work & 92.8 & & 91.6 & & 92.3 & \\
\hline Time dumm ies & & & & & & \\
\hline 1993 & 20.7 & & 11.3 & & 17.0 & \\
\hline 1994 & 22.6 & & 7.6 & & 16.6 & \\
\hline 1995 & 18.2 & & 10.9 & & 15.3 & \\
\hline 1996 & 20.9 & & 10.1 & & 16.6 & \\
\hline 1997 & 17.6 & & 60.1 & & 34.5 & \\
\hline Others dummies & & & & & & \\
\hline Bad health & 9.1 & & 27.3 & & 16.3 & \\
\hline High mental distress & 10.2 & & 15.1 & & 12.1 & \\
\hline Financial support from the state & 11.6 & & 17.2 & & 13.8 & \\
\hline Long - term une mployment & 29.8 & & 78.1 & & 48.9 & \\
\hline In debt & 38.0 & & 31.1 & & 35.3 & \\
\hline Pecuniary difficulties & 35.0 & & 41.2 & & 37.4 & \\
\hline Worse financial situation & 29.7 & & 41.2 & & 34.3 & \\
\hline Householder & 62.5 & & 54.2 & & 59.2 & \\
\hline Belgian & 88.7 & & 84.4 & & 87.0 & \\
\hline
\end{tabular}


Table 3: Descriptive Statistics -Women

\begin{tabular}{|c|c|c|c|c|c|c|}
\hline & \multirow{2}{*}{\multicolumn{2}{|c|}{$\begin{array}{c}\text { Spells 'E' } \\
398\end{array}$}} & \multicolumn{2}{|c|}{ Spells 'U' } & \multicolumn{2}{|c|}{ Spells 'E'+'U' } \\
\hline \multirow{2}{*}{$\begin{array}{l}\text { Number of observations } \\
\text { Continuous variables }\end{array}$} & & & \multicolumn{2}{|c|}{342} & \multicolumn{2}{|c|}{740} \\
\hline & \multicolumn{2}{|c|}{\begin{tabular}{|c|c|}
\multicolumn{2}{|c}{398} \\
Mean & St Dev
\end{tabular}} & Mean & St. Dev. & Mean & St. Dev. \\
\hline Age & 30.1 & 7.7 & 36.5 & 10.7 & 33.1 & 9.7 \\
\hline Experience & 10.6 & 8.5 & 18.2 & 11.9 & 14.4 & 11.0 \\
\hline Children & 0.8 & 0.9 & 0.8 & 1.0 & 0.8 & 1.0 \\
\hline Dummies & \multicolumn{2}{|c|}{ Frequence } & \multicolumn{2}{|c|}{ Frequence } & \multicolumn{2}{|c|}{ Frequence } \\
\hline \multicolumn{7}{|l|}{ Educational dummies } \\
\hline Primary school or no education & \multicolumn{2}{|l|}{5.3} & \multicolumn{2}{|l|}{17.5} & \multicolumn{2}{|l|}{10.9} \\
\hline Lower secondary school & \multicolumn{2}{|l|}{18.3} & \multicolumn{2}{|l|}{31.6} & \multirow{2}{*}{\multicolumn{2}{|c|}{24.5}} \\
\hline Upper secondary school & \multicolumn{2}{|l|}{38.7} & \multicolumn{2}{|l|}{37.4} & & 38.1 \\
\hline High school & \multicolumn{2}{|l|}{29.7} & \multicolumn{2}{|l|}{11.7} & 21.4 & \\
\hline University & 8.0 & & 1.8 & & 5.1 & \\
\hline Household dummies & & & & & & \\
\hline Children under 3 years & 18.8 & & 16.7 & & 17.8 & \\
\hline Not head of household & 84.2 & & 93.3 & & 88.4 & \\
\hline Married & 47.5 & & 47.2 & & 47.4 & \\
\hline Non married & 42.7 & & 24.4 & & 34.2 & \\
\hline Divorced, separated or widowed & 9.8 & & 28.4 & & 18.4 & \\
\hline Single & 8.3 & & 7.6 & & 8.0 & \\
\hline Couple & 75.6 & & 70.2 & & 73.1 & \\
\hline Single-parent & 16.1 & & 22.2 & & 18.9 & \\
\hline Additi onal child benefits & 4.0 & & 18.1 & & 10.5 & \\
\hline Regional membership dummies & & & & & & \\
\hline Brussels & 11.1 & & 10.8 & & 11.0 & \\
\hline Wallonia & 47.7 & & 48.8 & & 48.2 & \\
\hline Flanders & 41.2 & & 40.4 & & 40.8 & \\
\hline Job attributes dummies & & & & & & \\
\hline Part-time & 22.86 & & & & & \\
\hline No responsibility & 93.5 & & 96.2 & & 94.7 & \\
\hline Previous work & 91.5 & & 85.7 & & 88.8 & \\
\hline Time dummies & & & & & & \\
\hline 1993 & 21.6 & & 8.2 & & 15.4 & \\
\hline 1994 & 20.3 & & 5.6 & & 13.5 & \\
\hline 1995 & 19.1 & & 8.2 & & 14.1 & \\
\hline 1996 & 18.6 & & 6.4 & & 13.0 & \\
\hline 1997 & 20.4 & & 71.6 & & 44.0 & \\
\hline Others dummies & & & & & & \\
\hline Bad health & 8.0 & & 13.2 & & 11.4 & \\
\hline High mental distress & 20.4 & & 25.2 & & 22.6 & \\
\hline Financial support from state & 9.1 & & 20.2 & & 14.2 & \\
\hline Long-term unempl oyment & 32.7 & & 86.0 & & 57.3 & \\
\hline In debt & 30.7 & & 33.3 & & 31.9 & \\
\hline Pecuniary difficulties & 24.1 & & 41.5 & & 32.2 & \\
\hline Worse financial situation & 21.1 & & 36.3 & & 28.1 & \\
\hline Householder & 53.3 & & 51.5 & & 52.4 & \\
\hline Belgian & 94.2 & & 91.2 & & 92.8 & \\
\hline
\end{tabular}


Table 4: Results from the estimation of (1) - Selection equation

\begin{tabular}{|l|cc|cc|}
\hline \multicolumn{3}{|c|}{ MEN } & \multicolumn{3}{|c|}{ WOMEN } \\
\hline \multicolumn{4}{|c|}{} \\
Selection equation & -0.2788 & $(1.3838)$ & 0.0823 & $(1.6746)$ \\
\hline$\eta_{1}$ & 1.1511 & $(1.4816)$ & 1.7633 & $(1.6985)$ \\
$\eta_{1}$ & 0.1167 & $(0.0717)$ & 0.1064 & $(0.1026)$ \\
Age & $-0.0023^{* *}$ & $(0.0098)$ & -0.0025 & $(0.0015)$ \\
Age ${ }^{2}$ & 0.2228 & $(0.1891)$ & -0.2309 & $(0.1875)$ \\
Social activity & 0.2699 & $(0.2862)$ & -0.3152 & $(0.2644)$ \\
House allowances & $-1.1699^{* *}$ & $(0.1959)$ & $-1.6434^{\star *}$ & $(0.2341)$ \\
Long Term unemployment & 0.1643 & $(0.1911)$ & -0.0748 & $(0.1791)$ \\
Having loans & 0.0574 & $(0.1931)$ & -0.1669 & $(0.2127)$ \\
Financial Difficulties & -0.1872 & $(0.278)$ & 0.1327 & $(0.1816)$ \\
Mental distress & $-0.0508^{* *}$ & $(0.354)$ & -0.2112 & $(0.2351)$ \\
Kids less than 3 years & -0.5948 & $(0.2533)$ & -0.1199 & $(0.3285)$ \\
Bad health & -0.2678 & $(0.1959)$ & -0.1577 & $(0.1855)$ \\
Financial satisfaction & $-1.2931^{* *}$ & $(0.2588)$ & $-1.1742^{* *}$ & $(0.3105)$ \\
Not head of the household & $0.4449^{*}$ & $(0.2178)$ & 0.1728 & $(0.1978)$ \\
Householder & $-0.2786^{* *}$ & $(0.121)$ & -0.0139 & $(0.1093)$ \\
Number of children & -0.1561 & $(0.277)$ & 0.2182 & $(0.3253)$ \\
Belgian nationality & 0.2217 & $(0.2887)$ & 0.2058 & $(0.323)$ \\
Lower secondary school & $0.6405^{\star}$ & $(0.3191)$ & 0.3797 & $(0.319)$ \\
Upper secondary school & 0.5419 & $(0.3951)$ & 0.4605 & $(0.3641)$ \\
High school & 0.7112 & $(0.4126)$ & $0.9875^{*}$ & $(0.4851)$ \\
University & -0.3341 & $(0.2359)$ & $0.5058^{* *}$ & $(0.2196)$ \\
Married & -0.0819 & $(0.2317)$ & 0.328 & $(0.287)$ \\
Lone parenthood & 0.2158 & $(0.4509)$ & $-0.9416^{* *}$ & $(0.3814)$ \\
Additional child benefits & 0.2761 & $(0.2185)$ & -0.0975 & $(0.1855)$ \\
Living in Flanders & & & &
\end{tabular}

Table 5: Wage equation from (1)

\begin{tabular}{|l|cr|cr|}
\hline \multicolumn{3}{|c|}{ MEN } & \multicolumn{2}{c|}{ WOMEN } \\
\hline Wage equation & $10.0082^{\star *}$ & $(0.132)$ & $9.7449^{\star \star}$ & $(0.1855)$ \\
\hline$\alpha_{1}$ & $10.6209^{\star *}$ & $(0.1255)$ & $10.2367^{\star *}$ & $(0.1798)$ \\
$\alpha_{2}$ & $0.0254^{\star *}$ & $(0.007)$ & $0.0355^{\star *}$ & $(0.0095)$ \\
Experience (\# years) & $-0.0051^{\star *}$ & $(0.0022)$ & $-0.0095^{\star *}$ & $(0.0037)$ \\
Squared experience & $-0.1407^{\star *}$ & $(0.0485)$ & $-0.1772^{\star *}$ & $(0.0563)$ \\
Long term unemployed & 0.0251 & $(0.0538)$ & -0.0485 & $(0.0742)$ \\
Part-time worker & -0.0481 & $(0.0742)$ & $-0.1497^{\star *}$ & $(0.0409)$ \\
Responsibility & -0.002 & $(0.0741)$ & -0.0217 & $(0.074)$ \\
Previous professional experience & $-0.1821^{*}$ & $(0.0881)$ & 0.1143 & $(0.1404)$ \\
Lower secondary school & -0.0706 & $(0.0955)$ & 0.0862 & $(0.138)$ \\
Upper secondary school & 0.1359 & $(0.0993)$ & $0.3574^{* *}$ & $(0.1427)$ \\
High school & 0.1175 & $(0.1041)$ & $0.4632^{* *}$ & $(0.1489)$ \\
University
\end{tabular}


Table 6: Other parameters from (1)

\begin{tabular}{|l|cr|cr|}
\hline & \multicolumn{2}{|c|}{ MEN } & \multicolumn{2}{c|}{ WOMEN } \\
\hline$\rho$ & -0.2051 & $(0.3310)$ & $0.6500^{\star \star}$ & $(0.1465)$ \\
$\sigma^{2}$ & $0.0617^{\star \star}$ & $(0.005)$ & $0.0600^{\star *}$ & $(0.0081)$ \\
P11 & 0.1104 & $(0.0733)$ & 0.1462 & $(0.0945)$ \\
P12 & $0.5771^{\star \star}$ & $(0.1835)$ & $0.3491^{\star \star}$ & $(0.1124)$ \\
P21 & 0.0672 & $(0.0522)$ & $0.1978^{\star \star}$ & $(0.0616)$ \\
P22 & 0.2453 & $(0.1836)$ & $0.3069^{\star *}$ & $(0.0939)$ \\
\hline Log-likelihood & -330.8721 & \multicolumn{2}{|c|}{-394.7893} \\
Number of cases & 601 & & 740 & \\
\hline
\end{tabular}

Table 7: Men Selection equation : comparison of the estimates

\begin{tabular}{|l|cc|cc|}
\hline Coefficients & \multicolumn{2}{|c|}{ ML on (1) } & \multicolumn{2}{c|}{ RE - Probit Model } \\
\hline & & & & \\
$\eta_{1}$ & -0.2788 & $(1.3838)$ & 0.0290 & $(1.1723)$ \\
$\eta_{1}$ & 1.1511 & $(1.4816)$ & & \\
Age & 0.1167 & $(0.0717)$ & $0.1232^{\star}$ & $(0.0625)$ \\
Age & $-0.0023^{\star *}$ & $(0.0098)$ & $-0.0022^{* *}$ & $(0.0008)$ \\
Social activity & 0.2228 & $(0.1891)$ & 0.2028 & $(0.1652)$ \\
House allowances & 0.2699 & $(0.2862)$ & 0.2973 & $(0.2543)$ \\
Long Term unemployment & $-1.1699^{\star *}$ & $(0.1959)$ & $-1.1883^{\star *}$ & $(0.1839)$ \\
Having loans & 0.1643 & $(0.1911)$ & 0.1289 & $(0.1687)$ \\
Financial Difficulties & 0.0574 & $(0.1931)$ & 0.0657 & $(0.1772)$ \\
Mental distress & -0.1872 & $(0.278)$ & -0.1155 & $(0.2426)$ \\
Kids less than 3 years & $-0.0508^{\star *}$ & $(0.354)$ & -0.0354 & $(0.3016)$ \\
Bad health & -0.5948 & $(0.2533)$ & $-0.5688^{\star}$ & $(0.2237)$ \\
Financial satisfaction & -0.2678 & $(0.1959)$ & -0.2528 & $(0.1773)$ \\
Not head of the household & $-1.2931^{* *}$ & $(0.2588)$ & $-1.2849^{* *}$ & $(0.2272)$ \\
Householder & $0.4449^{\star}$ & $(0.2178)$ & $0.5134^{\star *}$ & $(0.1919)$ \\
Number of children & $-0.2786^{\star *}$ & $(0.121)$ & $-0.2995^{\star *}$ & $(0.1072)$ \\
Belgian nationality & -0.1561 & $(0.277)$ & -0.1096 & $(0.2413)$ \\
Lower secondary school & 0.2217 & $(0.2887)$ & 0.1657 & $(0.2710)$ \\
Upper secondary school & $0.6405^{\star}$ & $(0.3191)$ & $0.5811^{*}$ & $(0.2870)$ \\
High school & 0.5419 & $(0.3951)$ & 0.4607 & $(0.3354)$ \\
University & 0.7112 & $(0.4126)$ & 0.6506 & $(0.3778)$ \\
Married & -0.3341 & $(0.2359)$ & -0.3193 & $(0.2125)$ \\
Lone parenthood & -0.0819 & $(0.2317)$ & -0.0385 & $(0.1973)$ \\
Additional child benefits & 0.2158 & $(0.4509)$ & 0.2278 & $(0.4237)$ \\
Living in Flanders & 0.2761 & $(0.2185)$ & 0.2167 & $(0.1890)$ \\
\hline
\end{tabular}


Table 8: Men Wage equation : comparison of the estimates

\begin{tabular}{|l|cc|cc|}
\hline Coefficients & \multicolumn{2}{|c|}{ ML on (1) } & \multicolumn{2}{c|}{ RE - Linear Model } \\
\hline$\alpha_{1}$ & $10.0082^{\star \star}$ & $(0.132)$ & $10.5092^{\star *}$ & $(0.1580)$ \\
$\alpha_{2}$ & $10.6209^{\star *}$ & $(0.1255)$ & & \\
Experience (\# years) & $0.0254^{\star *}$ & $(0.007)$ & $0.0304^{\star *}$ & $(0.0088)$ \\
Squared experience & $-0.0051^{\star *}$ & $(0.0022)$ & $-0.0006^{\star}$ & $(0.0003)$ \\
Long term unemployed & $-0.1407^{\star \star}$ & $(0.0485)$ & $-0.1713^{\star *}$ & $(0.0473)$ \\
Part-time worker & 0.0251 & $(0.0538)$ & -0.0676 & $(0.0603)$ \\
Responsibility & -0.0481 & $(0.0742)$ & $-0.2142^{\star}$ & $(0.0947)$ \\
Previous professional & & & 0.0385 & $(0.0775)$ \\
experience & -0.002 & $(0.0741)$ & & \\
Lower secondary school & $-0.1821^{*}$ & $(0.0881)$ & -0.1327 & $(0.1058)$ \\
Upper secondary school & -0.0706 & $(0.0955)$ & -0.0423 & $(0.1080)$ \\
High school & 0.1359 & $(0.0993)$ & 0.0301 & $(0.1180)$ \\
University & 0.1175 & $(0.1041)$ & 0.1506 & $(0.1313)$ \\
& & & & \\
\hline
\end{tabular}

Table 9: Women Selection equation : comparison of the estimates

\begin{tabular}{|l|cc|cc|}
\hline Coefficients & \multicolumn{2}{|c|}{ ML on (1) } & \multicolumn{2}{c|}{ RE - Probit Model } \\
\hline & & & & \\
$\eta_{1}$ & 0.0823 & $(1.6746)$ & 0.8996 & $(1.3371)$ \\
$\eta_{1}$ & 1.7633 & $(1.6985)$ & & \\
Age & 0.1064 & $(0.1026)$ & 0.0950 & $(0.0763)$ \\
Age $^{2}$ & -0.0025 & $0.0015)$ & $-0.0022^{*}$ & $(0.0011)$ \\
Social activity & -0.2309 & $(0.1875)$ & -0.1582 & $(0.1572)$ \\
House allowances & -0.3152 & $(0.2644)$ & -0.3967 & $(0.2462)$ \\
Long Term unemployment & $-1.6434^{* *}$ & $(0.2341)$ & $-1.5645^{\star *}$ & $(0.2064)$ \\
Having loans & -0.0748 & $(0.1791)$ & -0.0799 & $(0.1633)$ \\
Financial Difficulties & -0.1669 & $(0.2127)$ & -0.0761 & $(0.1850)$ \\
Mental distress & 0.1327 & $(0.1816)$ & 0.0529 & $(0.1852)$ \\
Kids less than 3 years & -0.2112 & $(0.2351)$ & -0.2967 & $(0.2119)$ \\
Bad health & -0.1199 & $(0.3285)$ & -0.0514 & $(0.2659)$ \\
Financial satisfaction & -0.1577 & $0.1855)$ & -0.1856 & $(0.1820)$ \\
Not head of the household & $-1.1742^{* *}$ & $(0.3105)$ & $-1.0966^{* *}$ & $(0.2830)$ \\
Householder & 0.1728 & $(0.1978)$ & 0.0804 & $(0.1785)$ \\
Number of children & -0.0139 & $(0.1093)$ & 0.0172 & $(0.0941)$ \\
Belgian nationality & 0.2182 & $(0.3253)$ & 0.2331 & $(0.2884)$ \\
Lower secondary school & 0.2058 & $(0.323)$ & 0.1770 & $(0.2980)$ \\
Upper secondary school & 0.3797 & $(0.319)$ & 0.4023 & $(0.2900)$ \\
High school & 0.4605 & $(0.3641)$ & 0.4733 & $(0.3277)$ \\
University & $0.9875^{\star}$ & $(0.4851)$ & $1.0188^{*}$ & $(0.5093)$ \\
Married & $0.5058^{* *}$ & $(0.2196)$ & $0.4251^{*}$ & $(0.2069)$ \\
Lone parenthood & 0.328 & $(0.287)$ & 0.4204 & $(0.2684)$ \\
Additional child benefits & $-0.9416^{* *}$ & $(0.3814)$ & $-1.0027^{* *}$ & $(0.3354)$ \\
Living in Flanders & -0.0975 & $(0.1855)$ & -0.0000 & $(0.1708)$ \\
\hline
\end{tabular}


Table 10: Women Wage equation : comparison of the estimates

\begin{tabular}{|c|c|c|c|c|}
\hline Coefficients & \multicolumn{2}{|c|}{ ML on (1) } & \multicolumn{2}{|c|}{ RE - Linear Model } \\
\hline$\alpha_{1}$ & $9.7449^{* *}$ & $(0.1855)$ & $10.2473^{\star \star}$ & $(0.1743)$ \\
\hline$\alpha_{2}$ & $10.2367^{* *}$ & $(0.1798)$ & & \\
\hline Experience (\# years) & $0.0355^{\star \star}$ & (0.0095) & 0.0064 & $(0.0111)$ \\
\hline Squared experience & $-0.0095^{\star *}$ & $(0.0037)$ & 0.0001 & $(0.0004)$ \\
\hline Long term & & & $-0.0961^{*}$ & $(0.0451)$ \\
\hline unemployed & $-0.1772^{\star *}$ & $(0.0563)$ & & \\
\hline Part-time worker & -0.0485 & $(0.0742)$ & -0.0549 & $(0.0708)$ \\
\hline Responsibility & $-0.1497^{\star *}$ & $(0.0409)$ & $-0.1300^{* *}$ & $(0.0425)$ \\
\hline $\begin{array}{l}\text { Previous } \\
\text { professional }\end{array}$ & & & -0.0251 & $(0.0745)$ \\
\hline experience & -0.0217 & $(0.074)$ & & \\
\hline Lower secondary & 0.1143 & $(0.1404)$ & 0.0350 & $(0.1204)$ \\
\hline $\begin{array}{l}\text { Upper secondary } \\
\text { school }\end{array}$ & 0.0862 & (0.170 & 0.0778 & $(0.1179)$ \\
\hline High school & $0.3574^{\star \star}$ & $\begin{array}{l}(0.100) \\
(0.1427)\end{array}$ & $0.2997^{*}$ & $(0.1246)$ \\
\hline University & $0.4632^{\star *}$ & $(0.1489)$ & $0.4243^{* *}$ & $(0.1462)$ \\
\hline
\end{tabular}

Table 11: Mean Observed and Expected Wages

Mean wage for individuals moving into work

a) Observed wage:

b) Expected wage as predicted using (4)

c) Expected wage imputed when wage missing

Mean wage for individuals not moving into work

d) Expected wage as predicted using (4)

\begin{tabular}{|c|c|c|c|}
\hline Men & Women & Men & Women \\
\hline \multicolumn{2}{|c|}{$F B$} & & \\
\hline $43,345.97$ & $33,966.95$ & $1,074.52$ & 842.02 \\
\hline $43,031.76$ & $32,622.26$ & $1,066.73$ & 808.68 \\
\hline $42,207.88$ & $30,173.39$ & $1,046.31$ & 747.98 \\
\hline $39,668.18$ & $26,801.66$ & 983.35 & 664.40 \\
\hline
\end{tabular}

$1=40.3399 \mathrm{FB}$ 
Table 12: Observed Income Ratio $(<=1)$

\begin{tabular}{|c|c|c|c|c|c|c|}
\hline \multicolumn{7}{|c|}{ Observed Income Ratio: OIR } \\
\hline & \multicolumn{2}{|c|}{ Men } & \multicolumn{2}{|c|}{ Women } & Men & Women \\
\hline & \multicolumn{2}{|c|}{$\mathrm{N}^{\circ}$ of cases } & \multicolumn{2}{|c|}{$\mathrm{N}^{\circ}$ of cases } & $\%$ & $\%$ \\
\hline & Total & $O \mid R<=1$ & Total & $\mathrm{OIR}<=1$ & & \\
\hline Everybody & 363 & 12 & 398 & 36 & 3.31 & 9.05 \\
\hline Singles & 33 & 1 & 33 & 3 & 3.03 & 9.09 \\
\hline Couples & 82 & 4 & 74 & 7 & 4.88 & 9.46 \\
\hline Couples with children & 216 & 5 & 227 & 22 & 2.31 & 9.69 \\
\hline Single parents & 3 & 0 & 2 & 0 & 0 & 0 \\
\hline $\begin{array}{l}\text { Single parents with } \\
\text { children }\end{array}$ & 29 & 2 & 62 & 4 & 6.9 & 6.45 \\
\hline $\begin{array}{l}\text { Long Term } \\
\text { unemployment }\end{array}$ & 108 & 4 & 130 & 17 & 3.7 & 13.08 \\
\hline
\end{tabular}

Table 13: Estimated Income Ratios for all the individuals (EIR $\_1<=1$ )

\begin{tabular}{|c|c|c|c|c|c|c|}
\hline \multicolumn{7}{|c|}{ Estimated Income Ratio: ElR_1 } \\
\hline & \multicolumn{2}{|c|}{ Men } & \multicolumn{2}{|c|}{ Women } & Men & Women \\
\hline & \multicolumn{2}{|c|}{$\mathrm{N}^{\circ}$ of cases } & \multicolumn{2}{|c|}{$\mathrm{N}^{\circ}$ of cases } & $\%$ & $\%$ \\
\hline & Total & $E I R<=1$ & Total & $E I R<=1$ & & \\
\hline Everybody & 601 & 16 & 740 & 160 & 2.66 & 21.62 \\
\hline Singles & 69 & 1 & 59 & 16 & 1.45 & 27.12 \\
\hline Couples & 164 & 11 & 151 & 26 & 6.71 & 17.22 \\
\hline Couples with children & 329 & 3 & 390 & 56 & 0.91 & 14.36 \\
\hline Single parents & 5 & 0 & 4 & 0 & 0 & 0 \\
\hline $\begin{array}{l}\text { Single parents with } \\
\text { children }\end{array}$ & 34 & 1 & 136 & 66 & 2.94 & 48.53 \\
\hline $\begin{array}{l}\text { Long Term } \\
\text { unemployment }\end{array}$ & 294 & 14 & 424 & 126 & 4.76 & 29.72 \\
\hline
\end{tabular}


Table 14: Estimated Income Ratios for all the individuals (EIR $\_2<=1$ )

\begin{tabular}{|c|c|c||c|c||c||c|}
\hline \multicolumn{7}{|c|}{ Estimated Income Ratio: EIR_2 } \\
\hline & \multicolumn{2}{|c|}{ Men } & \multicolumn{2}{|c|}{ Women } & Men & Women \\
\cline { 3 - 5 } & \multicolumn{2}{|c|}{$\mathrm{N}^{\circ}$ of cases } & \multicolumn{2}{|c|}{$\mathrm{N}^{\circ}$ of cases } & $\%$ & $\%$ \\
\hline Everybody & 601 & 27 & 740 & 160 & 4.49 & 21.62 \\
& & & & & & \\
Singles & 69 & 2 & 59 & 13 & 2.9 & 22.03 \\
Couples & 164 & 15 & 151 & 29 & 9.15 & 19.21 \\
Couples with children & 329 & 8 & 390 & 57 & 2.43 & 14.62 \\
Single parents & 5 & 4 & 4 & 0 & 80 & 0 \\
Single parents with & & & & & & \\
children & 34 & 2 & 136 & 61 & 5.88 & 44.85 \\
Long Term & & & & & & \\
unemployment & 294 & 18 & 424 & 121 & 6.12 & 28.54 \\
\hline
\end{tabular}

Table 15: Estimated Income Ratios for all individuals fictionally employed $\left(\left(\mathrm{EIR} \_2=\mathrm{EIR} \_1\right)<=1\right)$

\begin{tabular}{|c|c|c|c|c|c|c|}
\hline \multicolumn{7}{|c|}{ Estimated Income Ratio: EIR for the Unemployed } \\
\hline & \multicolumn{2}{|c|}{ Men } & \multicolumn{2}{|c|}{ Women } & Men & Women \\
\hline & \multicolumn{2}{|c|}{$\mathrm{N}^{\circ}$ of cases } & \multicolumn{2}{|c|}{$\mathrm{N}^{\circ}$ of cases } & \multirow[t]{2}{*}{$\%$} & \multirow[t]{2}{*}{$\%$} \\
\hline & Total & $E I R<=1$ & Total & $\begin{array}{l}|E| R<= \\
1\end{array}$ & & \\
\hline Everybody & 238 & 13 & 342 & 95 & 5.46 & 27.78 \\
\hline Singles & 36 & 3 & 126 & 3 & 8.33 & 2.38 \\
\hline Couples & 82 & 1 & 77 & 7 & 1.22 & 9.09 \\
\hline Couples with children & 113 & 9 & 163 & 22 & 7.96 & 13.5 \\
\hline Single parents & 2 & 3 & 2 & 0 & 150 & 0 \\
\hline children & 5 & 0 & 74 & 4 & 0 & 5.41 \\
\hline $\begin{array}{c}\text { Long Term } \\
\text { unemployment }\end{array}$ & 186 & 12 & 294 & 90 & 6.45 & 30.61 \\
\hline & & & & & & \\
\hline & & & & & & \\
\hline
\end{tabular}


Table 16: Mean Observed and Estimated Income Ratios for workers

\begin{tabular}{|l|l|l|l|l|}
\hline & \multicolumn{2}{|c|}{ MEN } & \multicolumn{2}{c|}{ WOMEN } \\
\hline Variable & $\mathrm{N}^{\circ}$ & Mean & $\mathrm{N}^{\circ}$ & Mean \\
\hline & & & & \\
\hline Mean (OIR) & 363 & 2.2693 & 398 & 1.8158 \\
\hline Mean (EIR_1) & 363 & 2.1695 & 398 & 1.6289 \\
\hline Mean (EIR_2) & 363 & 2.1640 & 398 & 1.7293 \\
\hline
\end{tabular}

\subsection{Figures}

\section{Legend for figure 5-6:}

cfami=1 "Single"

cfami $=2$ "Couples without children aged less than 6"

cfami $=3$ "Couples with children aged less than 6"

cfami $=4$ "Single parents without children aged less than 6"

cfami $=5$ "Single parents with children aged less than 6"s

\section{Legend for Figures 7, 8 and 9.}

The graphs have been built using the following variables:

1. Men: gender $=1$;

2. Women: gender $=2$

3. destin $=1$ : not moving into work

4. destin=0: moving into work;

We have generated a new variable defined "sex_destin"= gender* destin. Its values are:

1. sex_destin=0: Men and women moving into work during the observation period;

2. sex_destin=1: Men fictionally employed;

3. sex_destin $=2$ : Women fictionally employed;

4. Total: all the individuals in the sample

\section{Legend for Figures 11 and 12:}

The graphs have been built using the following variables:

1. Men: gender $=1$;

2. Women: gender $=2$;

3. ltu:=1: long-term unemployment spell in the past; 
4. ltu=0: no long-term unemployment spell in the past;

We have generated a new variable defined "sex_ltu"= gender* ltu. Its values are:

1. sex_ltu=0: Men and women haven't experienced long-term unemployment;

2. sex_ltu=1: Long-term unemployed men;

3. sex_ltu=0: Long-term unemployed women

4. Total: all the individuals

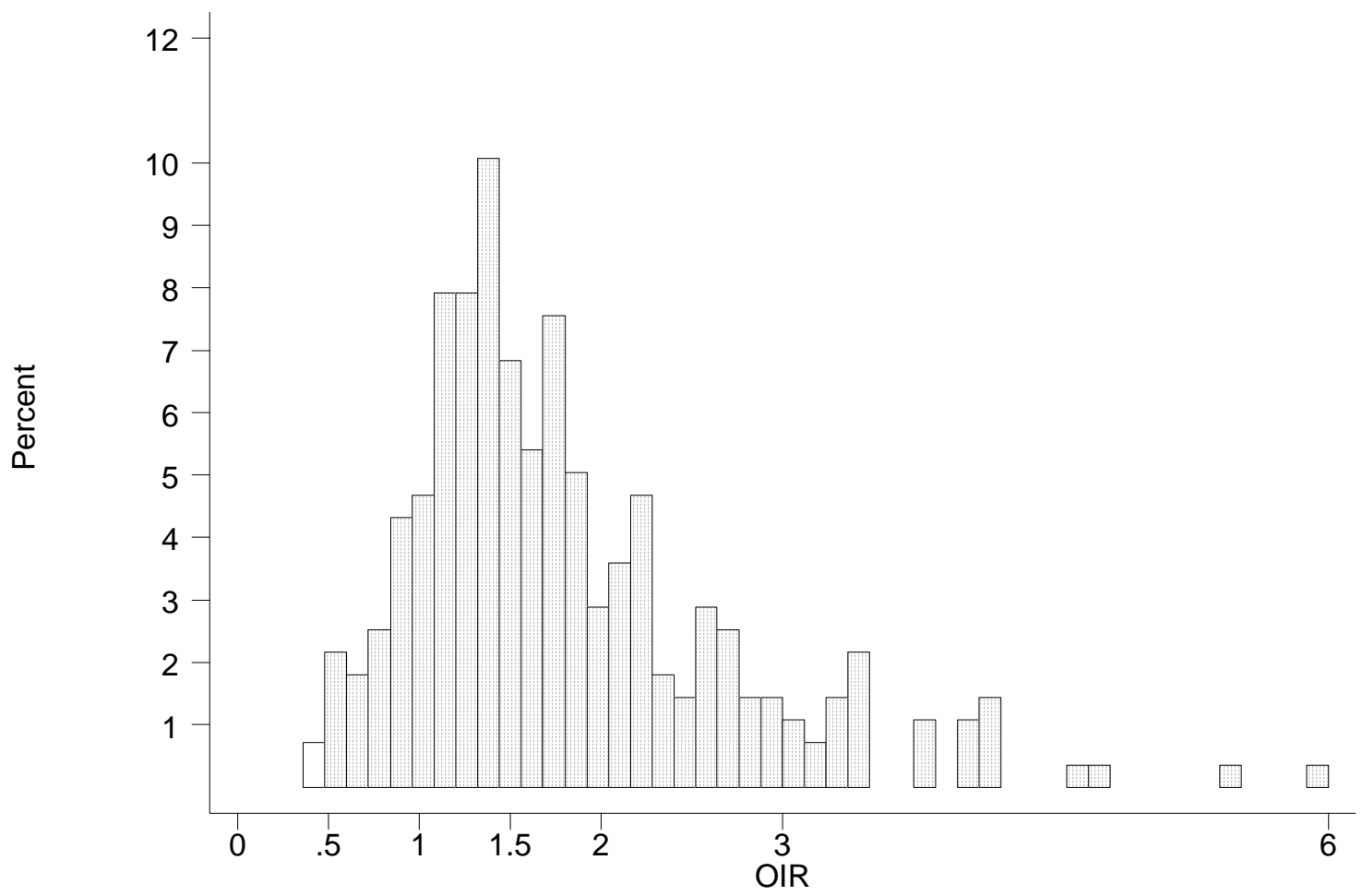

Figure 1: Women : OIR 


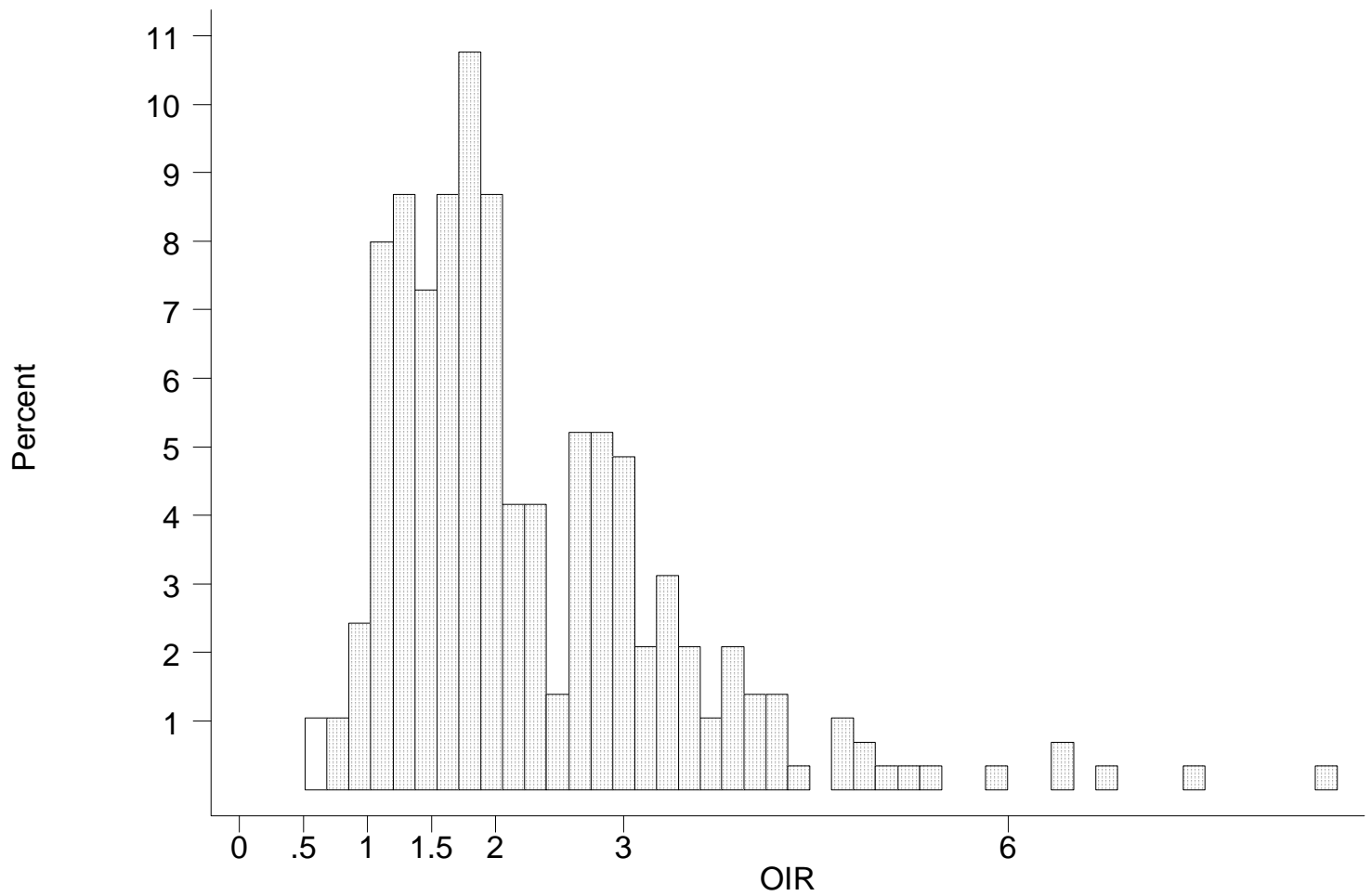

Figure 2: Men : OIR 

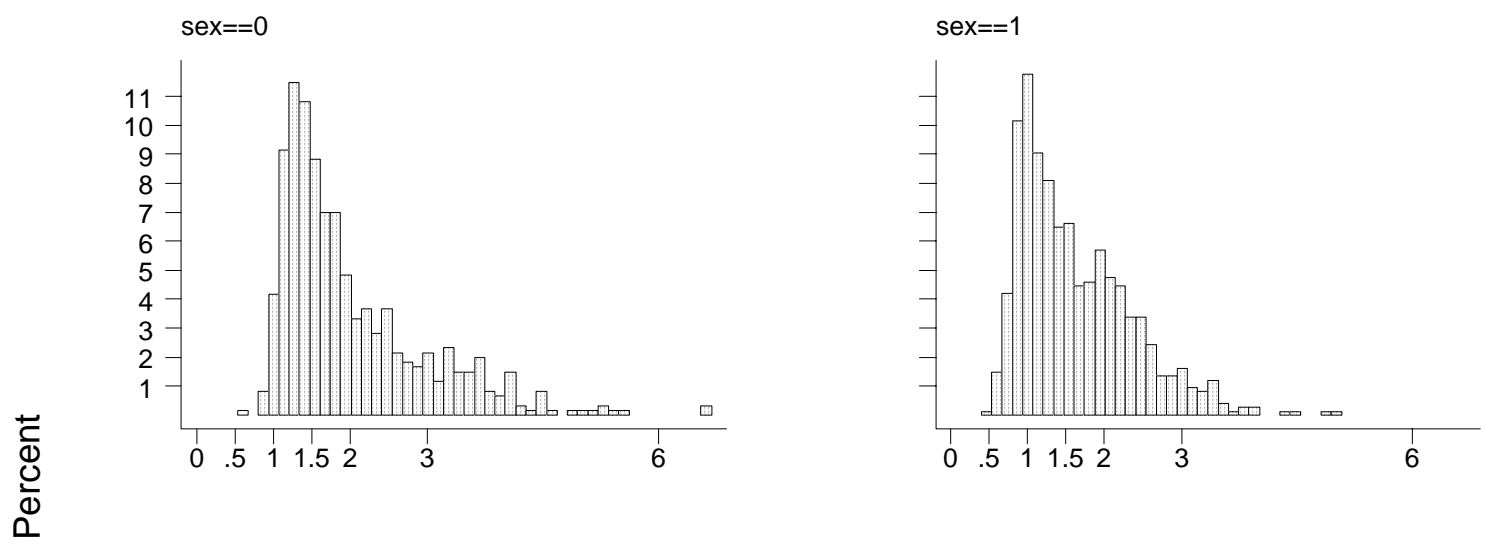

EIR 1

Histograms by sex

Figure 3: EIR_1 distinguished by sex 


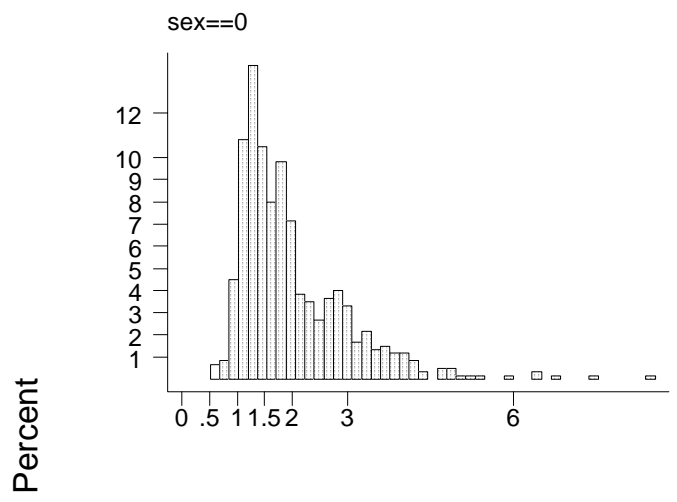

sex $==1$

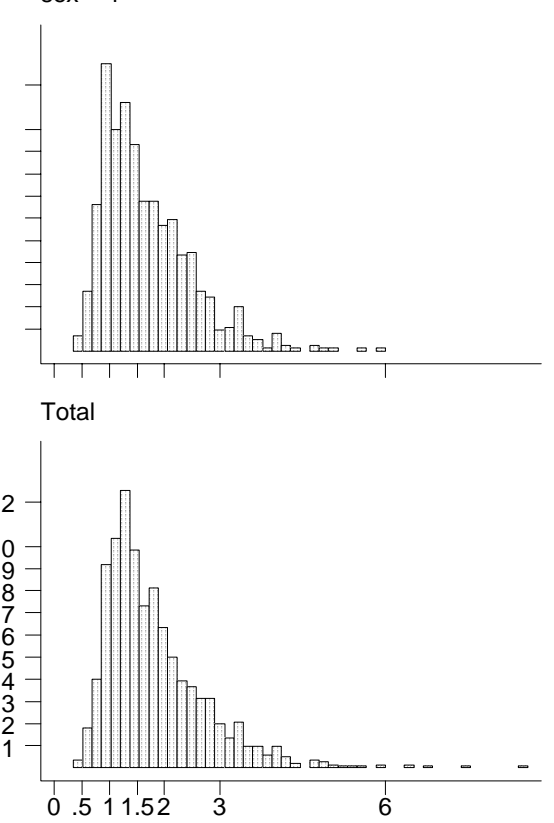

EIR_2

Histograms by sex

Figure 4: EIR_2 distinguished by sex 


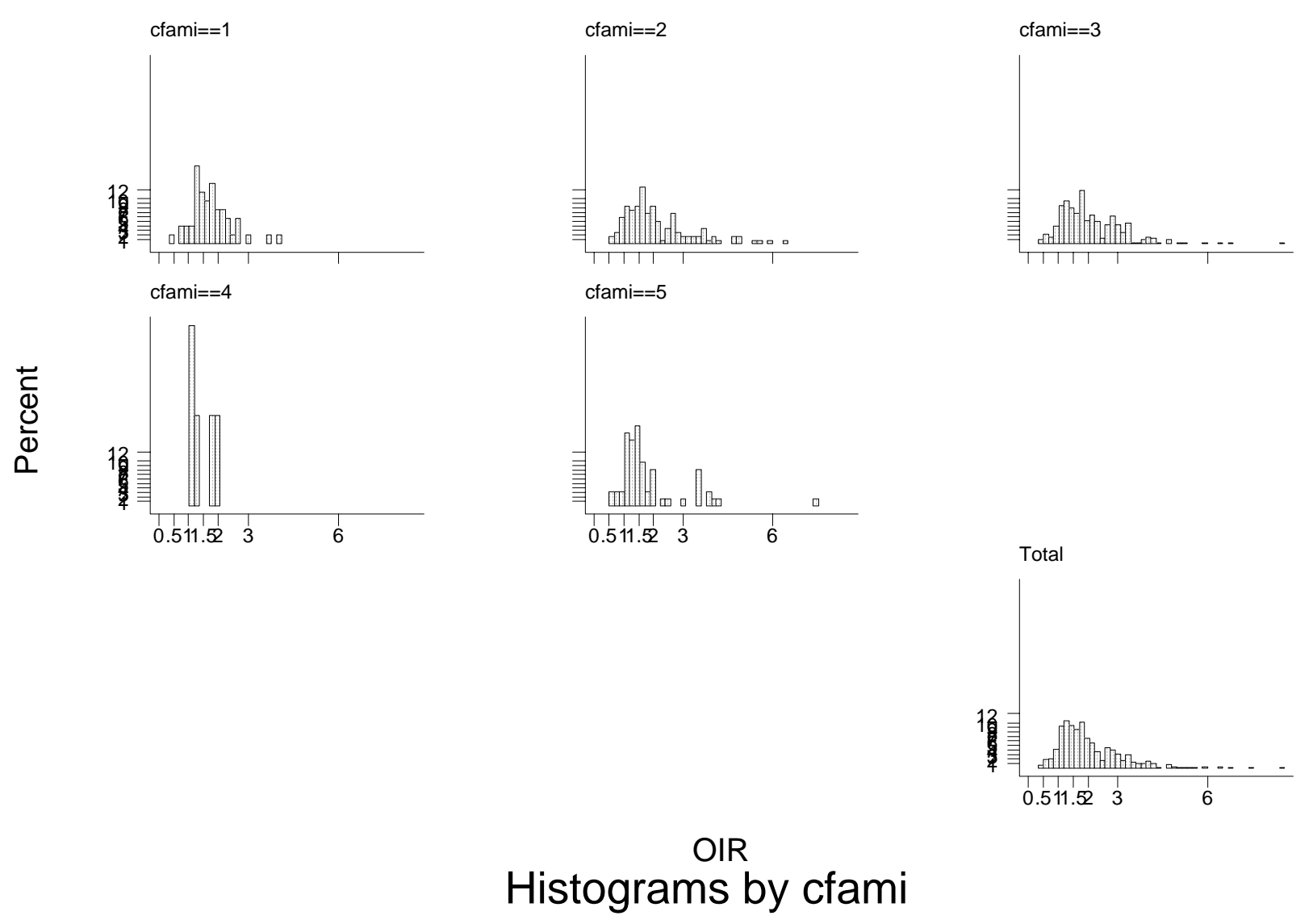

Figure 5: OIR according to the household composition (cfami - see legend) 


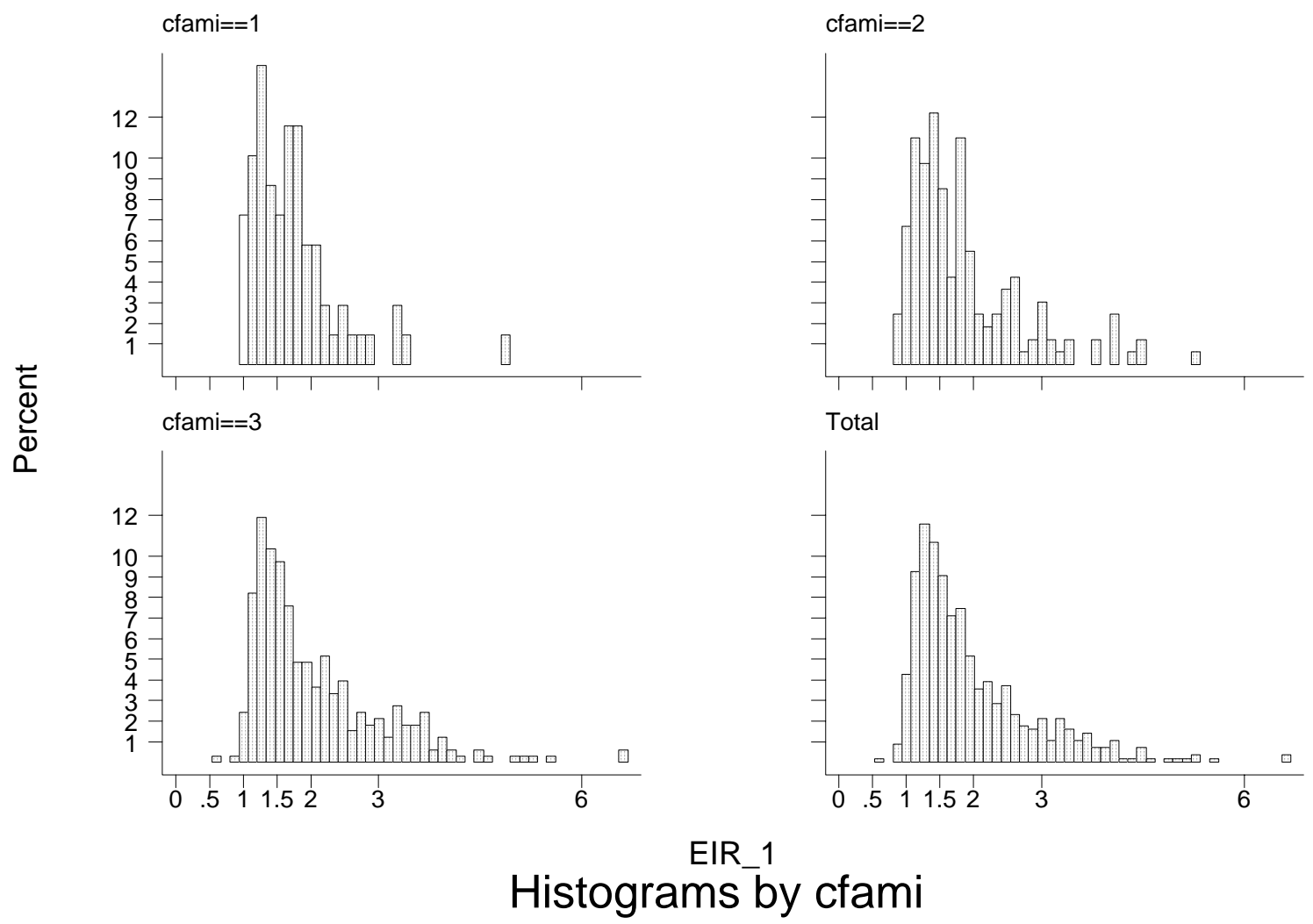

Figure 6: Men: EIR_1 according to the household composition (cfami - see legend) 


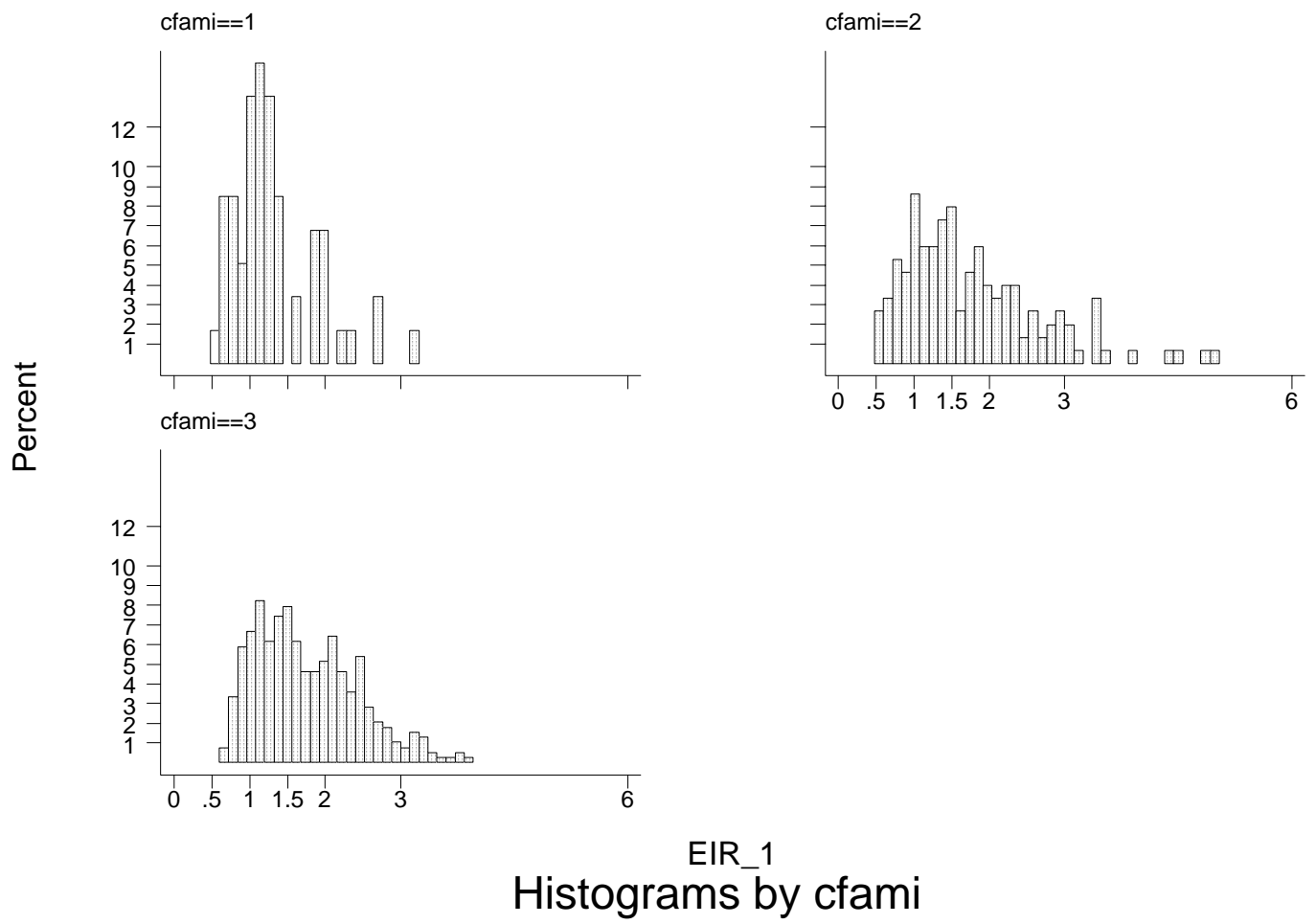

Figure 7: Women: EIR_1 according to the household composition (cfami - see legend)

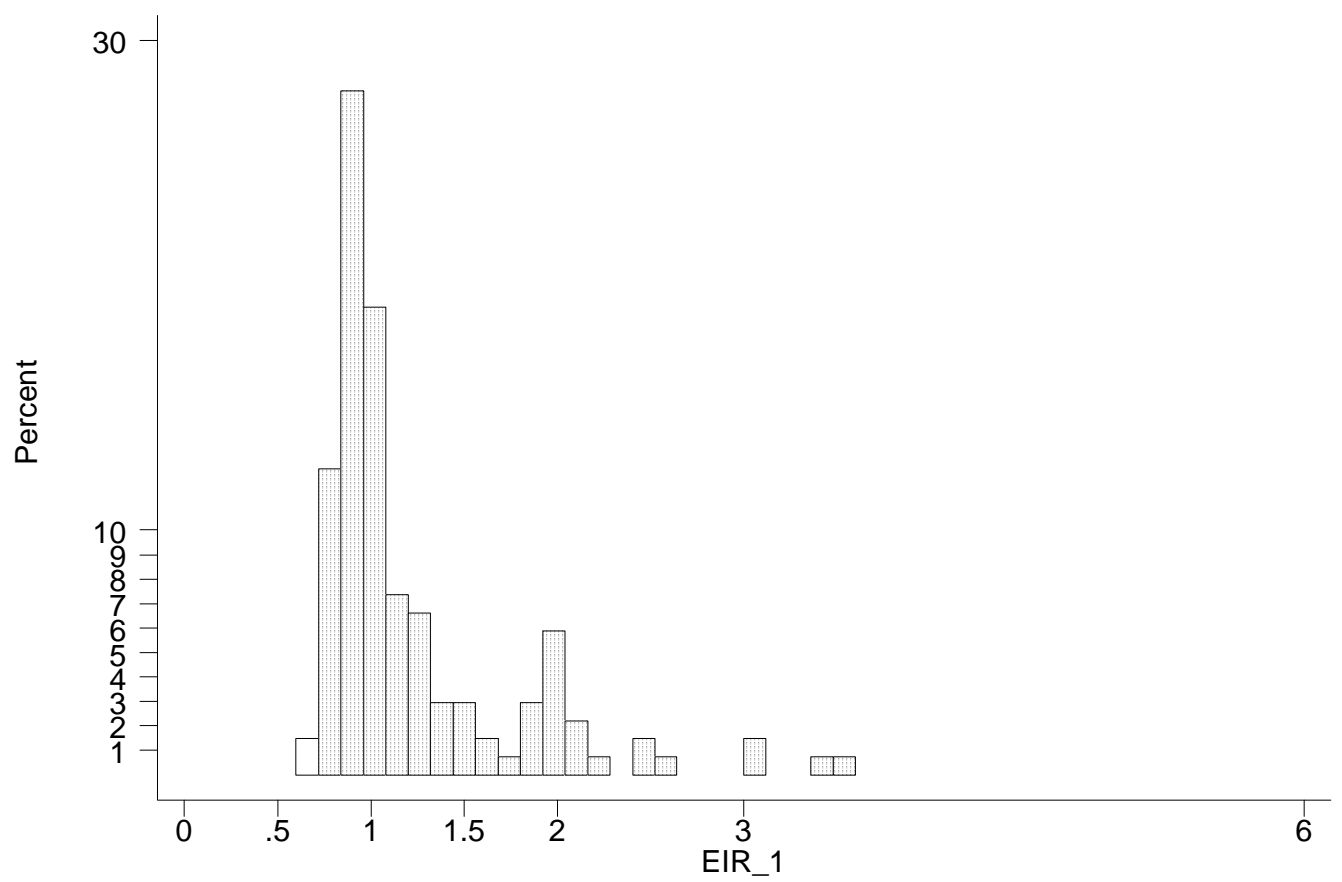

Figure 8: Women: EIR_1 lone parents with children aged less than 6 


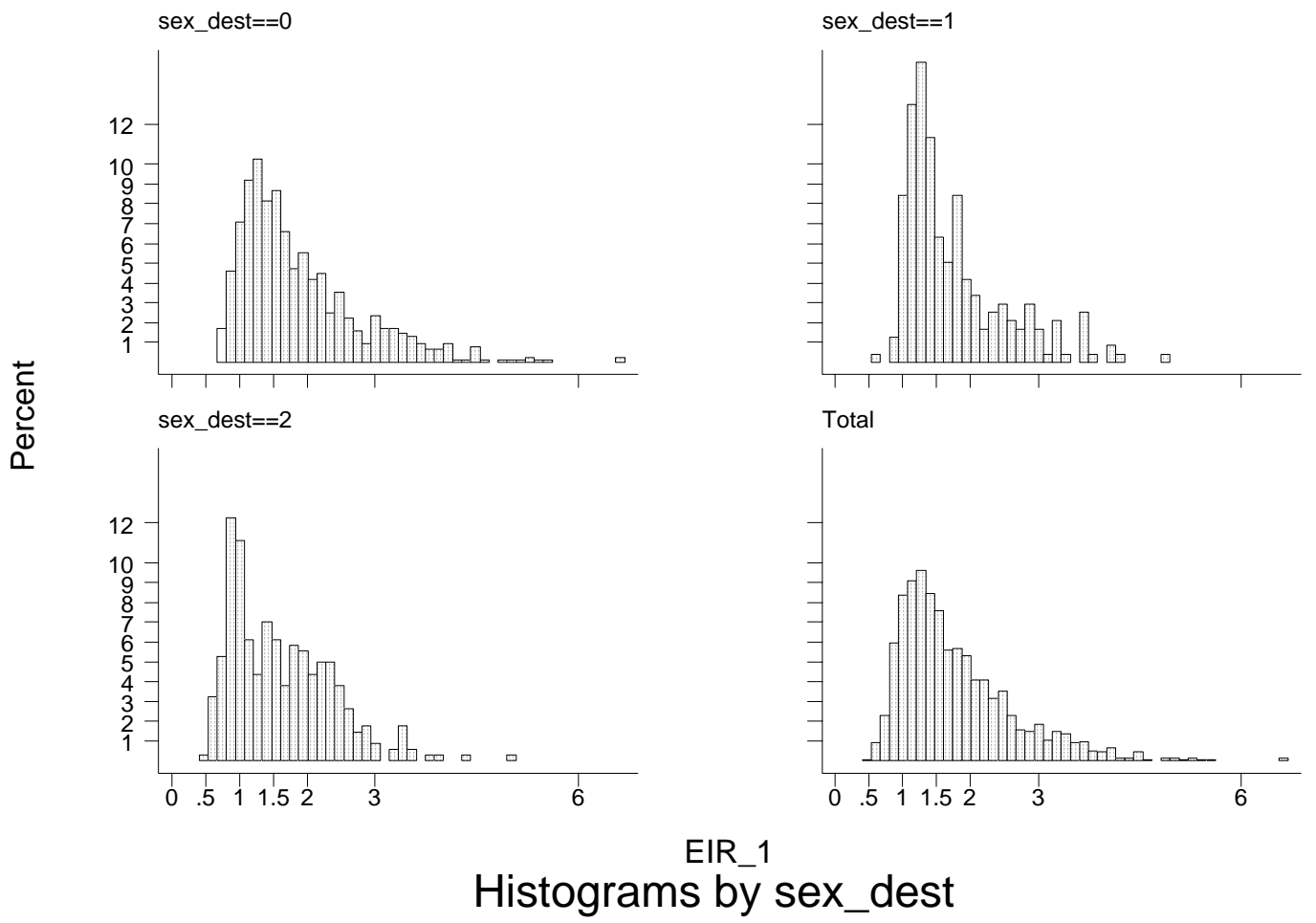

Figure 9: EIR_1 distinguished by sex \& destination (see legend) 


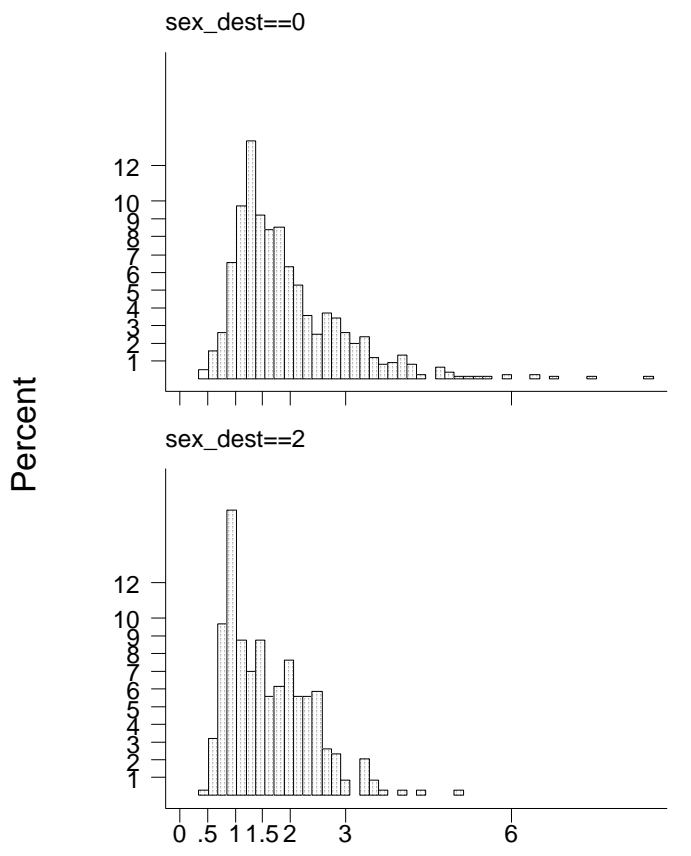

sex_dest==1

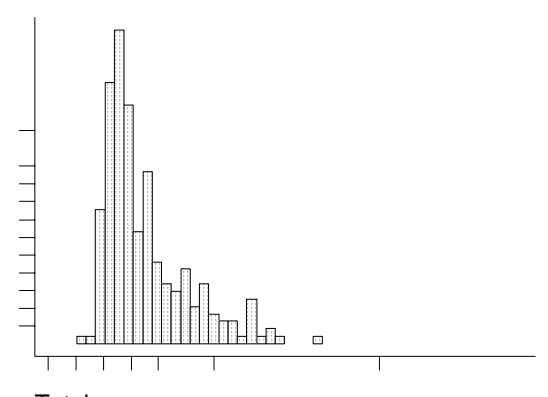

Total

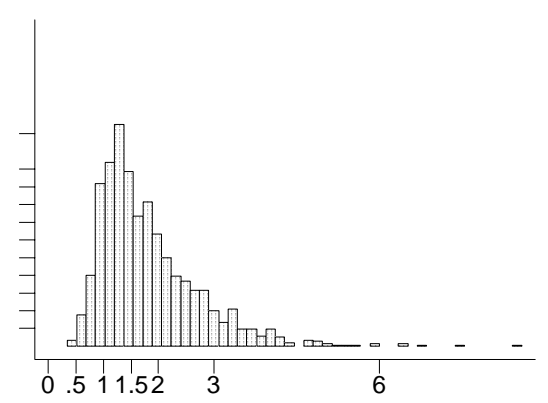

EIR_2

Histograms by sex_dest

Figure 10: EIR_2 distinguished by sex \& destination (see legend) 

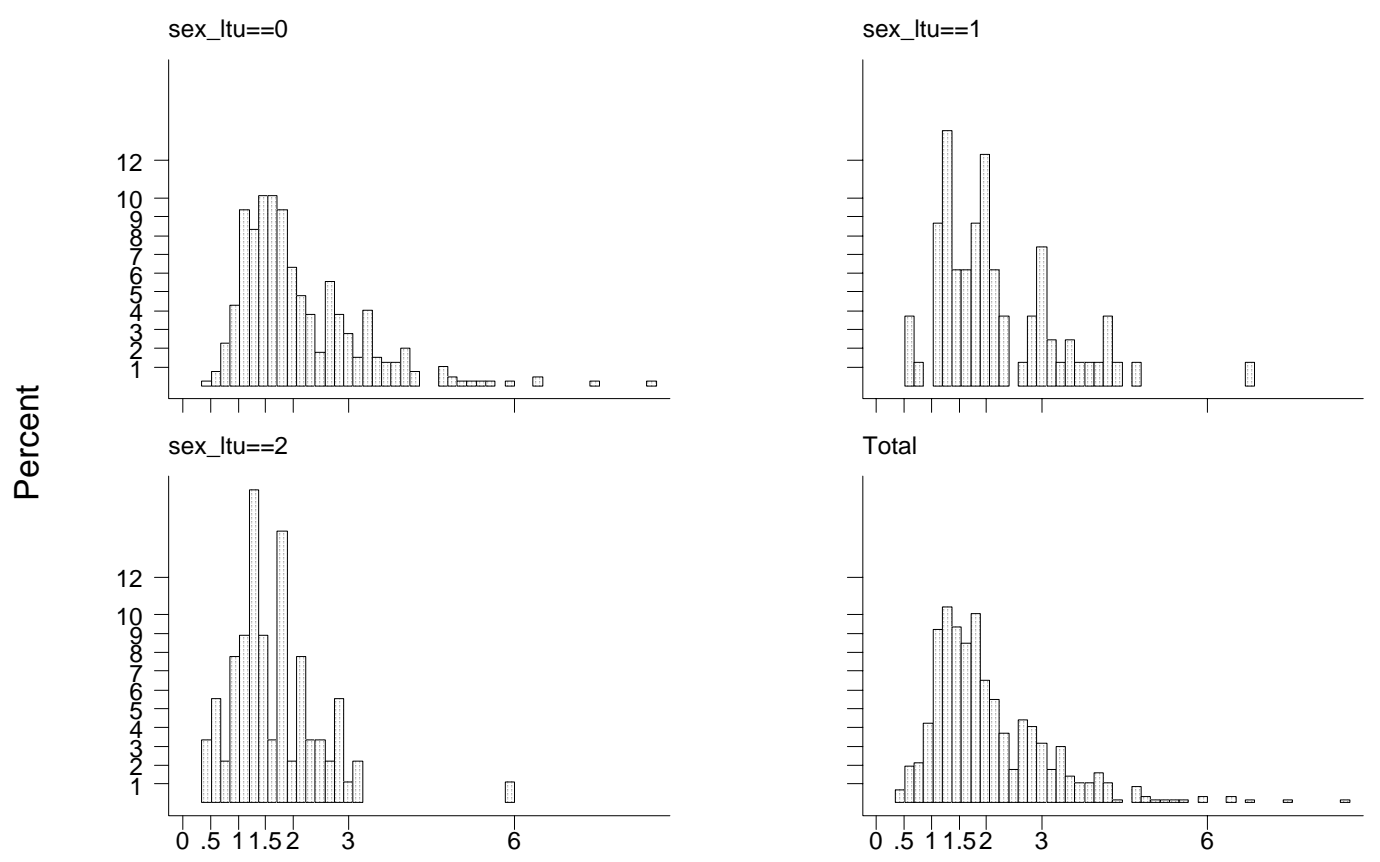

Histograms by sex_Itu

Figure 11: OIR distinguished by sex \& long-term unemployment experience (see legend) 

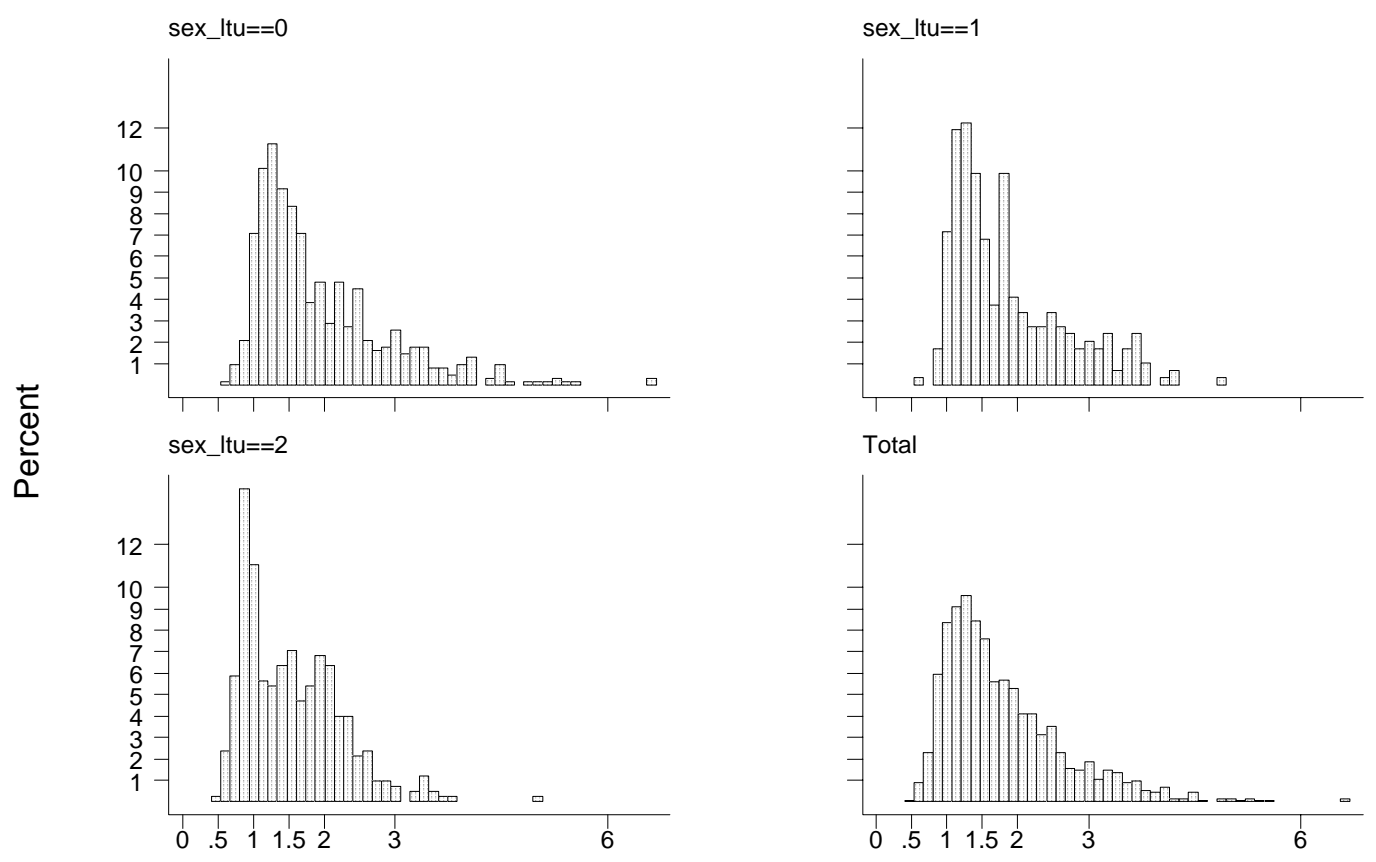

Histograms by sex_ltu

Figure 12: EIR_1 distinguished by sex \& long-term unemployment experience (see legend) 